\title{
Primary cancer cell culture: mammary-optimized vs conditional reprogramming
}

\author{
Ahmad M Alamri1,2,*, Keunsoo Kang3,4,*, Svenja Groeneveld1,5,*, Weisheng Wang1, \\ Xiaogang Zhong6, Bhaskar Kallakury7, Lothar Hennighausen³, Xuefeng Liu7 and \\ Priscilla A Furth ${ }^{1,8}$
}

1Department of Oncology, Lombardi Comprehensive Cancer Center, Georgetown University, Washington, District of Columbia, USA

2Department of Clinical Laboratory Sciences, College of Applied Medical Sciences, King Khalid University, Abha, Saudi Arabia ${ }^{3}$ Laboratory of Genetics and Physiology, National Institute of Diabetes and Digestive and Kidney Diseases, National Institutes of Health, 8 Center Drive, Bethesda, Maryland, USA

${ }^{4}$ Department of Microbiology, Dankook University, Cheonan, Republic of Korea 5Department Pharmazie, Ludwig-Maximilians-Universität München, Munich, Germany ${ }^{6}$ Department of Biostatistics, Bioinformatics and Biomathematics, Georgetown University, Washington, District of Columbia, USA

${ }^{7}$ Department of Pathology, Lombardi Comprehensive Cancer Center, Georgetown University, Washington, District of Columbia, USA

8Department of Medicine, Lombardi Comprehensive Cancer Center, Georgetown University, Washington, District of Columbia, USA

*(A M Alamri, K Kang and S Groeneveld contributed equally to this work)

\author{
Correspondence \\ should be addressed \\ to P A Furth \\ Email \\ Paf3@georgetown.edu
}

\begin{abstract}
The impact of different culture conditions on biology of primary cancer cells is not always addressed. Here, conditional reprogramming (CRC) was compared with mammaryoptimized EpiCult-B (EpiC) for primary mammary epithelial cell isolation and propagation, allograft generation, and genome-wide transcriptional consequences using cancer and non-cancer mammary tissue from mice with different dosages of Brca 1 and $p 53$. Selective comparison to DMEM was included. Primary cultures were established with all three media, but CRC was most efficient for initial isolation $(P<0.05)$. Allograft development was faster using cells grown in EpiC compared with CRC $(P<0.05)$. Transcriptome comparison of paired CRC and EpiC cultures revealed 1700 differentially expressed genes by passage 20. CRC promoted Trp53 gene family upregulation and increased expression of epithelial differentiation genes, whereas EpiC elevated expression of epithelial-mesenchymal transition genes. Differences did not persist in allografts where both methods yielded allografts with relatively similar transcriptomes. Restricting passage $(<7)$ reduced numbers of differentially expressed genes below 50 . In conclusion, CRC was most efficient for initial cell isolation but EpiC was quicker for allograft generation. The extensive culture-specific gene expression patterns that emerged with longer passage could be limited by reducing passage number when both culture transcriptomes were equally similar to that of the primary tissue. Defining impact of culture condition and passage on the transcriptome of primary cells could assist experimental design and interpretation. For example, differences that appear with passage and culture condition are potentially exploitable for comparative studies targeting specific biological networks in different transcriptional environments.
\end{abstract}

\section{Key Words}

- primary cell culture

- mammary cancer

- Brca1

- genetically engineered mouse models

- transcriptome 


\section{Introduction}

Isolation of primary tumor cells from patient samples is a first step for many types of genetic, biochemical, and pharmacological experiments relevant to personalized cancer treatment (Mitra et al. 2013). Retention of genetic characteristics and progenitor cells from the original cancer are important goals for culture methodology. Genetically engineered mouse models (GEMM) of breast cancer serve as preclinical translational analogs for the study of breast cancer pathophysiology and technology development for precision medicine. Here, we used Brca1-deficient (Jones et al. 2005, 2008, Nakles et al. 2013a,b) and Brca1-replete (Tilli et al. 2003, Díaz-Cruz et al. 2011) mouse models of breast cancer to compare transcriptional consequences and cancer progenitor cell retention of two different primary cancer epithelial cell culture methodologies: the mammary epithelial cell-optimized EpiCult (B) system (Stemcell Technologies, Vancouver, BC, Canada) (Yamaji et al. 2009) and the epithelial-selective conditionally reprogrammed culture (CRC) technology (Liu et al. 2012, Suprynowicz et al. 2012, Palechor-Ceron et al. 2013, Chapman et al. 2014, Saenz et al. 2014, Ligaba et al. 2015). Previously, we employed time-lapse microscopy to show that mammary epithelial cells from wild-type (WT) and Brca1-deficient GEMM undergo morphological changes consistent with epithelial-mesenchymal transition (EMT) within 4 days of initial culture in EpiCult (B) (EpiC) (Nakles et al. 2013b). The experiments presented here were initiated because CRC was reported to retain cuboidal architecture of the mammary epithelial cell (Saenz et al. 2014). However, mandatory inclusion of the irradiated fibroblast feeder layer or conditioned media burdens the technique and the required Rho kinase (ROCK) inhibitor Y-27632 has the potential to alter a number of cellular processes (Olson 2008). For that reason, we considered it sensible to directly compare biological and transcriptional consequences of these two prominent choices for initial isolation and propagation of primary mammary epithelial cells under 2D adherent conditions to further define the advantages and disadvantages of each approach. Previous work reported significant gene expression differences in 3D cultures of undifferentiated human mammary epithelial cells grown as mammospheres compared with growth under differentiating conditions on collagen (Dontu et al. 2003).

Epithelial-mesenchymal transition (EMT) is observed in many 2D epithelial cell culture conditions and is associated with specific changes in cell morphology and gene expression including upregulation of transforming growth factor beta (TGFB) signaling pathways (MorenoBueno et al. 2009) and dedifferentiation, including loss of estrogen receptor alpha (ERa) expression (Novaro et al. 2003). In cancer biology, EMT has been mechanistically linked to metastasis, chemotherapy resistance, and preservation of cancer progenitor cells (Drasin et al. 2011, Luo et al. 2015).

CRC reduces TGFB signaling (Ligaba et al. 2015) and promotes p63 expression, a gene linked to 'stemness' in some tissues, but nevertheless expressed in fully differentiated mammary myoepithelial cells (Suprynowicz et al. 2012, Assefnia et al. 2014, Chapman et al. 2014, Melino et al. 2015). Differentiation of skin keratinocytes is suppressed in CRC with lower levels of keratin gene expression and increased levels of hTERT (Liu et al. 2012, Palechor-Ceron et al. 2013, Chapman et al. 2014). Removal from CRC and placement into alternative media allows the cells to differentiate with increased levels of keratin expression, illustrating that some genetic changes imposed by CRC can be reversible (Suprynowicz et al. 2012). Treatment of breast cancer cells with the ROCK inhibitor used for CRC, Y-27632, is known to decrease actomyosin interaction (Bhandary et al. 2015). Actin cytoskeleton changes are integral to EMT (Haynes et al. 2011).

The natural history of GEMM utilized for this study includes development of a range of triple-negative mammary cancers from moderately well-differentiated to undifferentiated adenocarcinomas and more EMT-like spindloid/sarcomatoid carcinomas (Diaz-Cruz et al. 2010, Nakles et al. 2013a). The same spectrum of histopathology is found in human triple-negative breast cancers (Lehmann et al. 2011). One of the human mesenchymal stem-like (MSL) triple-negative histologies demonstrates TGFBR3 over-expression (Jovanović et al. 2014).

Here, we show that both methodologies can be effectively used for isolation and propagation of primary non-cancer and cancer mammary epithelial cells. The major advantage of the CRC approach was a significantly higher success rate for initial culture (95\%). Benefits of EpiC include a less burdensome culture methodology and faster allograft development. Both culture conditions were associated with characteristic transcriptional changes upon prolonged passage $(>20)$. Limiting passage $(<7)$ reduced the magnitude of these changes equivalently for both conditions. Differences found in the paired cells after prolonged culture, for example, variances in allograft formation, upregulation of p53 pathways under CRC, and upregulation of TGFBR3 under EpiC, could be exploited in targeted studies of cancer biology and therapy.

Published by Bioscientifica Ltd. 


\section{Materials and methods}

\section{Mouse models}

Primary mammary epithelial cells were isolated from cancer and non-cancer mammary tissue from six GEMMs and parental strain wild-type (WT) C57Bl/6 mice (30-46 g): Brca1floxed (fl)11/wild-type (WT)/mouse mammary tumor virus (MMTV)-Cre/Trp53-/+ (Brca1///p53-/+) $n=6 /$ cancer, $n=3 /$ non-cancer; Brca1 fl11/fl11/ MMTV-Cre/Trp53-/+ (Brca1-//p53-/+) $n=2 /$ cancer, $n=1 /$ non-cancer; tet-op-CYP19A1 MMTV-reverse tetracycline-controlled transactivator(rtTA)/Trp53-/+/ MMTV-Cre $\left(C Y P 19 A 1^{\text {53-/+ }}\right) n=1 /$ cancer; Brca1 fl11/WT/MMTV-Cre/tetop-CYP19A1/Trp53-/+I- (Brca1-/+/CYP19A1/p53-/+) n=4/cancer; Brca1fl11/ fl11/MMTV-Cre/Trp53-/+/MMTV-rtTA/tet-op-Esr1

(Brca1-//p53-/+/rtTA/Esr1) $n=1 /$ cancer, $n=1 /$ non-cancer; tet-op-simian virus 40 $T \quad$ antigen $^{M M T V-t e t r a c y c l i n e ~ t r a n s a c t i v a t o r(T A) / t e t-o p-E s r 1 ~} \quad$ (TagtTA/Esr1) $n=1 /$ non-cancer; and WT $n=1 /$ non-cancer. GEMMs were generated at the Georgetown University, weaned before puberty, and genotyped using tail DNA (Transnetyx, Inc, Cordova, TN, USA). For allograft experiments, 6-week-old athymic nude (NU (NCr)-Foxn1nu) female mice $(n=13)$ (Harlan Laboratories, Inc, Frederick, MD, USA) (26-30g) were acclimatized 1 week before primary cell injection into thoracic and inguinal mammary fat pads through a skin incision under isoflurane anesthesia (four sites/ mouse $/ 10^{6}$ mammary epithelial cancer cells/site in $25 \mu \mathrm{L}$ $\mathrm{PBS} / 25 \mu \mathrm{L}$ Matrigel) (BD Biosciences, Franklin Lakes, NJ, USA)/1cc syringe/27-gauge needle). All mice were housed in barrier zones in single-sex sterilized ventilated cages with corn-cob bedding (1-4 mice per cage) with access to water ad libitum/irradiated Picolab rodent diet 20 (5053) (Labdiet, St Louis, MO, USA) under $12 \mathrm{~h}$ darkness:12 h light cycles at the Georgetown University. Irradiated Picolab rodent diet 20 (5053) (Labdiet, St Louis, MO, USA) was provided with the exception of doxycycline-containing diet (Bio-Serv, Frenchtown, NJ, USA) for CYP19A1p53-/+ mice. Mice were monitored weekly with measurement of palpable tumors and killed by $\mathrm{CO}_{2}$ inhalation followed by cervical dislocation when mice reached 6 months of age (allograft experiments), 12 months of age (GEMM), or palpable tumors $>1 \mathrm{~cm}^{3}$, whichever occurred first. Cancer and non-cancer mammary tissues were removed at necropsy and divided for isolation of viable mammary epithelial cells, formalin fixation, or frozen at $-80^{\circ} \mathrm{C}$.

\section{Primary mammary epithelial cell culture}

Cells were isolated using EpiCult-B Mouse Medium Kit (Stemcell Technologies, Vancouver, BC, Canada) (Nakles et al. 2013b) and divided for culture under CRC: F medium containing 25\% Ham's F-12 nutrient mix
(Thermo Fisher Scientific) supplemented with $25 \mathrm{ng} / \mathrm{mL}$ hydrocortisone, $5 \mu \mathrm{g} / \mathrm{mL}$ insulin, $0.1 \mathrm{nmol} / \mathrm{L}$ cholera toxin (Sigma-Aldrich), $0.125 \mathrm{ng} / \mathrm{mL}$ epidermal growth factor, $10 \mu \mathrm{g} / \mathrm{mL}$ gentamicin (Thermo Fisher Scientific), 250ng/mL Fungizone (Thermo Fisher Scientific), and $5 \mu \mathrm{mol} / \mathrm{L}$ ROCK inhibitor Y-27632 (Enzo Life Sciences, Farmingdale, NY, USA) in the presence of irradiated Swiss 3T3-J2 mouse fibroblast feeder cells (Chapman et al. 2010, Liu et al. 2012); or under EpiC: EpiCult-B Basal medium (mouse) supplemented with EpiCult-B Basal Proliferation Supplements (mouse), 10 ng/mL recombinant human epidermal growth factor (rhEGF), 10\% fetal bovine serum (FBS) (Stemcell Technologies, Vancouver, BC, Canada), and $100 \mu \mathrm{g} / \mathrm{mL}$ streptomycin/penicillin (Thermo Fisher Scientific) and/or complete Dulbecco's modified Eagle's medium (DMEM) containing 10\% fetal bovine serum (FBS), $100 \mu \mathrm{g} / \mathrm{mL}$ penicillin, $100 \mu \mathrm{g} / \mathrm{mL}$ streptomycin, and $100 \mu \mathrm{g} / \mathrm{mL}$ glutamine (Thermo Fisher Scientific) at $37^{\circ} \mathrm{C}$ with $5 \% \mathrm{CO}_{2}$. For EpiC culture, fibroblast contamination was reduced by incubating cells in a first flask to allow fibroblasts to adhere (3-4h) and then transferring the epithelial cell enriched non-adherent cells to a second flask for expansion (Darcy et al. 2000). Cells were viably frozen at different passage numbers and re-cultured when needed. Digital images were taken using EVOS XL Core Cell Imaging System or Olympus IX+71 microscope/ Olympus DP70 camera/DP Controller v3.2.1.276 software (Olympus America Inc, Center Valley, PA, USA).

\section{Immunohistochemistry and pathological examination}

Tissue and cell pellets were fixed in 10\% buffered formalin (Thermo Fisher Scientific) overnight at $4^{\circ} \mathrm{C}$, embedded in paraffin and $5 \mu \mathrm{m}$ sections were stained with hematoxylin and eosin (H\&E), or used for immunohistochemistry (IHC) following antigen retrieval with citrate buffer. The primary antibodies were as follows: cytokeratin, Wide Spectrum Screening (CK) (1:625, Z0622; Dako), cell pellets (1:120), tissue, P53 protein (CM5; Novocastra), NCL-p53-CM5p (1:200), Ki67 NCL+L+Ki67+MM (1:120; Leica), anti-p63 (4A4) mouse monoclonal primary antibody $(1: 1,790$ 4509; Ventana Medical Systems, Inc, Tucson, AZ, USA), transforming growth factor, beta receptor III (TGFBR3) (sc6199, 1:300; Santa Cruz Biotechnology), and cluster of differentiation (CD)140A/platelet-derived growth factor receptor, alpha polypeptide (PDGFRA) (APA5, 1:100; BioLegend, San Diego, CA, USA) to label murine fibroblasts (Gawade et al. 2016). A board-certified academic pathologist (B.V.S.K.) blinded to sample

Published by Bioscientifica Ltd 


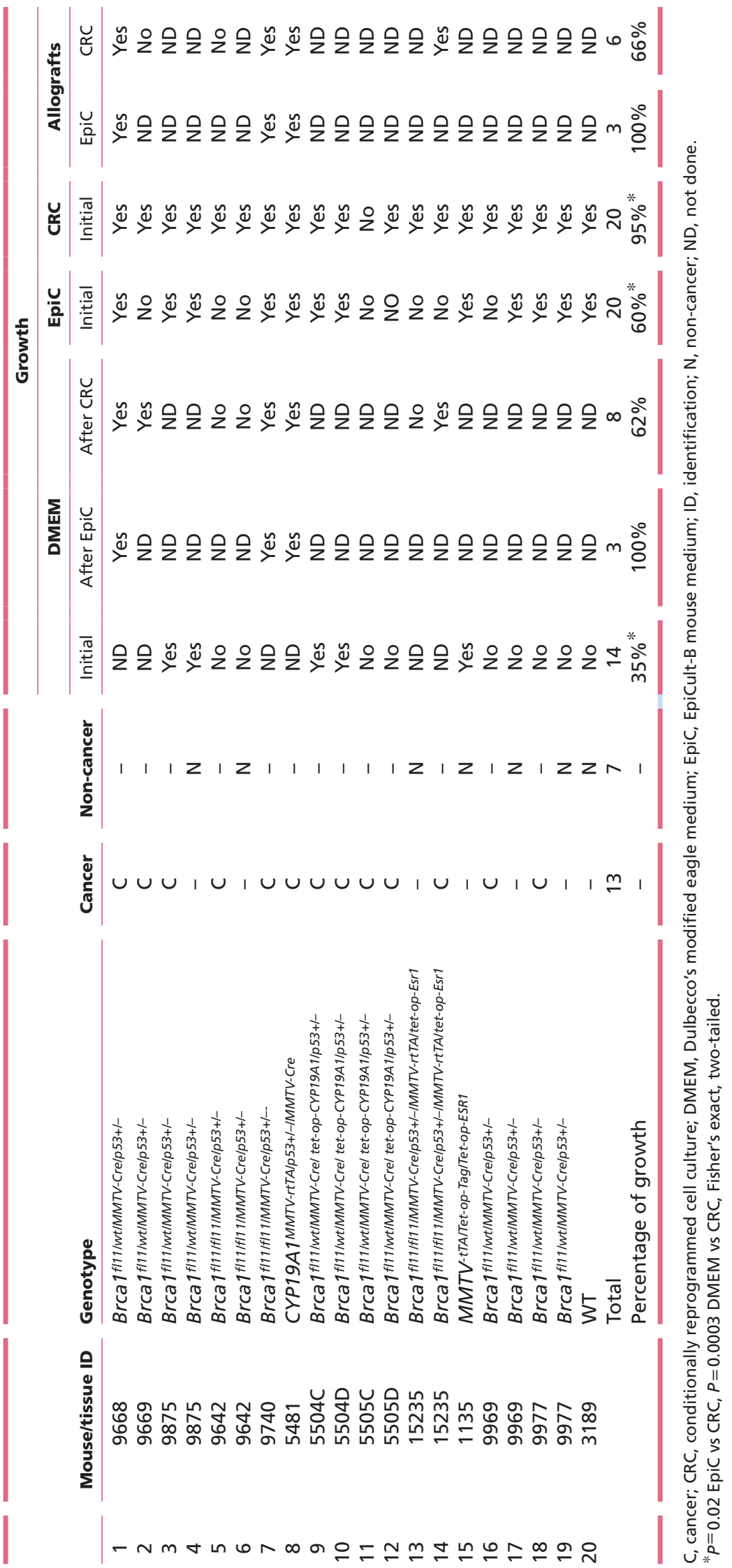



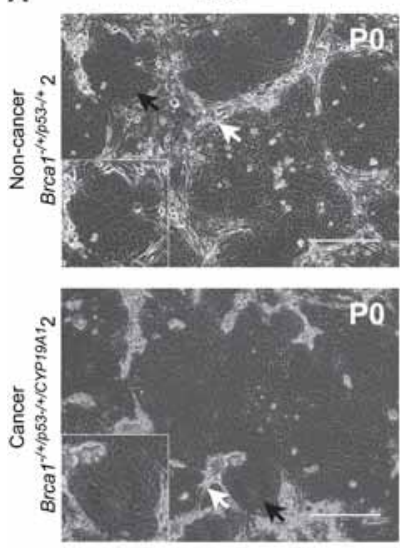

B
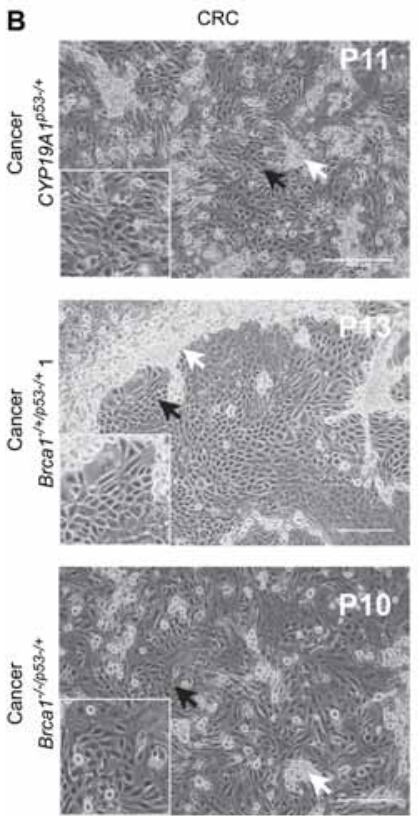

EpiC
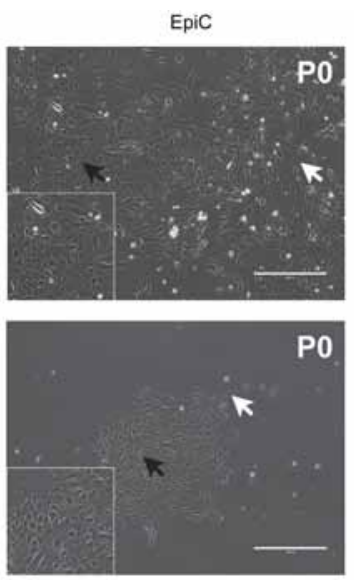

EpiC
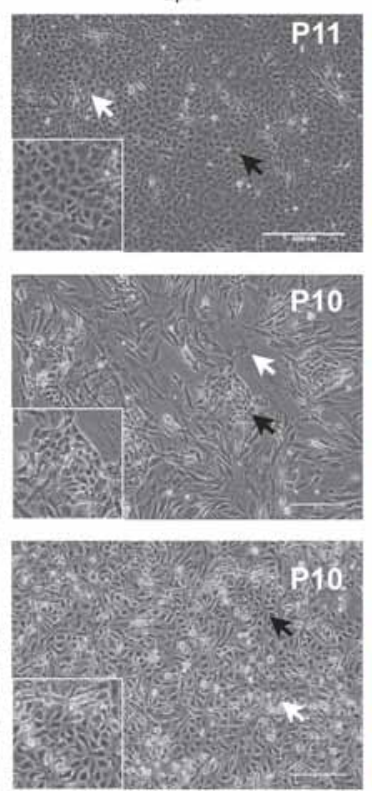

DMEM
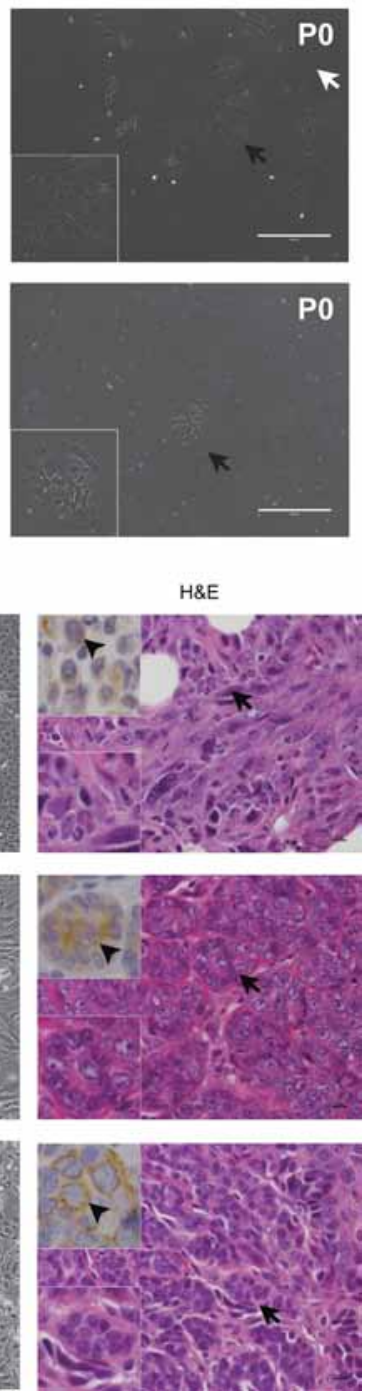

Figure 1

Cultured primary mammary epithelial cells were derived from mammary cancers and non-cancerous mammary tissue of genetically engineered mice. (A) Phase-contrast images of primary cells cultured in CRC, EpiC, and DMEM 5 days following initial plating without passage. Cells derived from non-cancerous and cancerous mammary gland tissue from the same Brca1 $1^{-1 / 1 / 153-1+}$ mouse. Bottom left inset shows magnified image of area indicated by black arrows on larger images. (B) Phase-contrast images of CYP19A1 1553-l+, Brca1-1//p53-1+ 1, and Brca1-1/p53-// primary cells cultured in CRC and EpiC and H\&E images of the mammary cancers from which the cells were derived. Bottom left inset shows magnified image of area indicated by black arrow on larger phase-contrast and H\&E images. Top left shows representative image of pancytokeratin IHC (arrowheads). Passage number indicated top right (phase-contrast images). Black arrows indicate mammary epithelial cells. White arrows indicate fibroblast or feeder cells. Phase-contrast images taken at $10 x$. Size bars $=400 \mu \mathrm{M}$. H\&E images taken at $40 x$. Size bars $=10 \mu \mathrm{M}$. CRC, conditionally reprogrammed cells; EpiC, EpiCult-B; H\&E, hematoxylin and eosin; $P$, passage. identity read histology. Digital images were taken using Nikon Eclipse E800 Microscope/NIS-Elements BR 4.30.02 64-bit software (Nikon Instruments Inc).

\section{Polymerase chain reaction (PCR) and reverse transcriptase-PCR (RT-PCR)}

DNA was extracted from cell pellets using PureLink Genomic DNA Mini Kit (Thermo Fisher Scientific) or formalin-fixed, paraffin-embedded (FFPE) allograft sections employing QuickExtract FFPE DNA Extraction Kit (Epicenter, Madison, WI, USA) and PureLink Genomic DNA Mini Kit (Thermo Fisher Scientific) or RNA extracted using an RNeasy Mini Kit (Qiagen), quantified (Nanodrop, Thermo Fisher Scientific), and $1 \mu \mathrm{g}$ total RNA used to prepare complement DNA (cDNA) (qScript cDNA
Synthesis Kit, Quanta Biosciences Inc, Gaithersburg, MD, USA) for detection of Brca1 exon 11 deletion (forward: 5'-GGGTAGTTTGTAAGCATCCA-3', reverse: 5'-GCCTGTTCCTCCCCTTGTATA-3'), tet-op-CYP19A1 (forward: 5'-CGAGCTCGGTACCCGGGTCG-3', reverse: 5'-CAGGCATGGCTTCAGGCACGA-3') (Díaz-Cruz et al. 2011), MMTV-Cre (forward: 5'-GTGAACGTGCAAAA CAGGCT-3', reverse: 5'-CGGTGCTAACCAGCGTTT TC-3'), and $A c t b$ ( $\beta$-actin) (forward: 5'-ATCGTGGGC CGCCCTAGGCA-3', reverse: TGGCCTTAGGGTTCAGA GGG-3') (GoTaq Green Master Mix, Promega). PCR (30 cycles: $1 \mathrm{~m}: 95^{\circ} \mathrm{C}, 1 \mathrm{~m}: 58^{\circ} \mathrm{C}, 3 \mathrm{~m}: 72^{\circ} \mathrm{C}$ ) and RT-PCR (30 cycles: $1 \mathrm{~m}: 95^{\circ} \mathrm{C}, 1 \mathrm{~m}: 60^{\circ} \mathrm{C}, 3 \mathrm{~m}: 72^{\circ} \mathrm{C}$ ) products were visualized by ethidium bromide staining after electrophoresis on agarose gels (Bio-Rad Universal Hood II, Bio-Rad). 
A

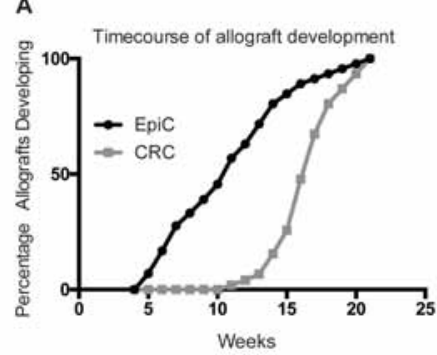

B

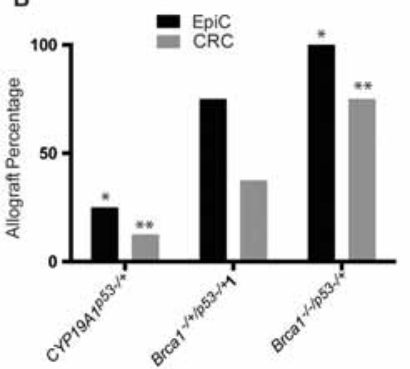

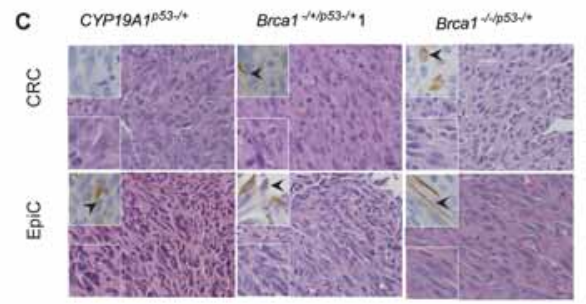
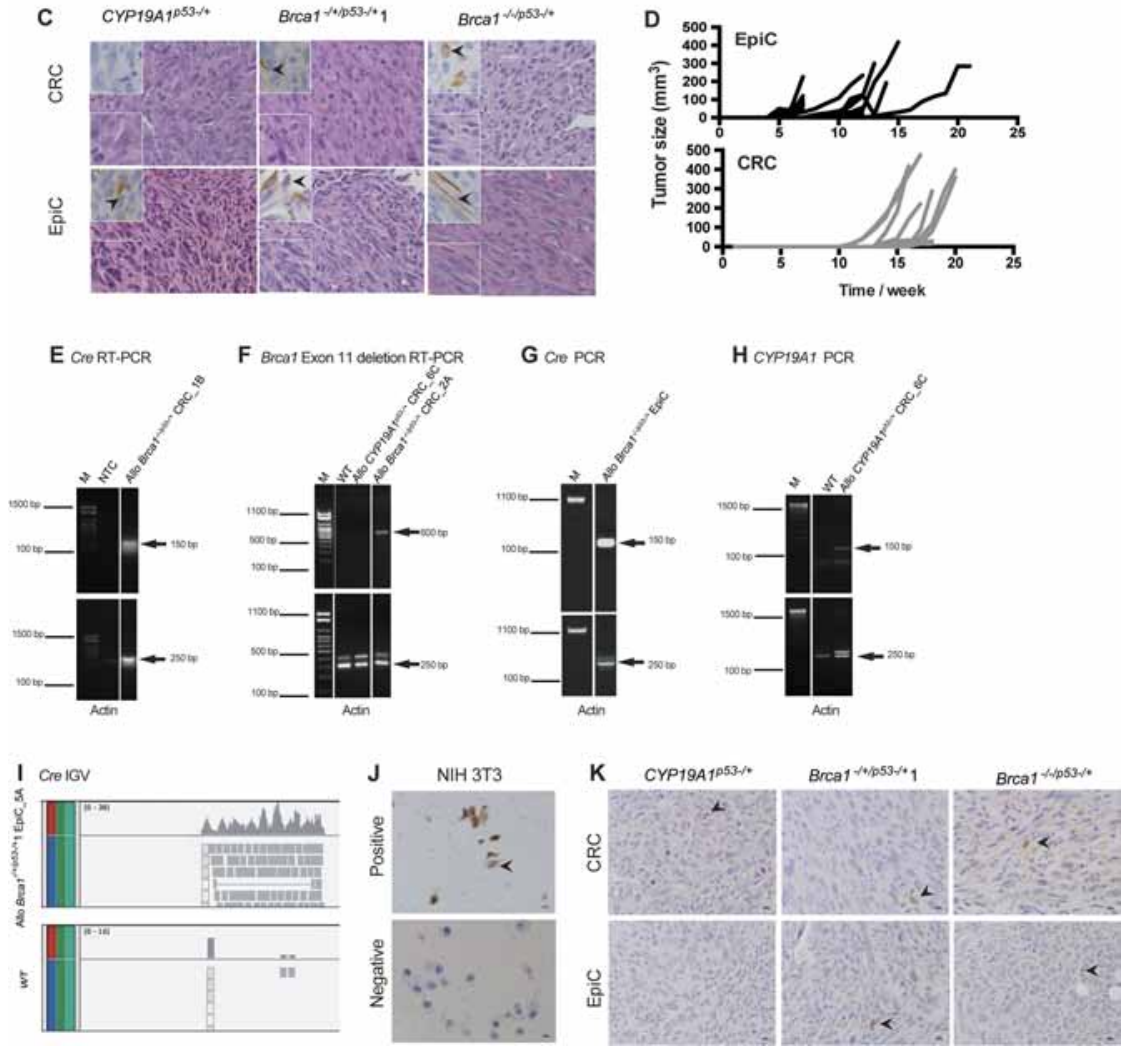

Figure 2

Allograft generation from cells grown under EpiC and CRC conditions. (A) Time course of percentage of injected sites developing into palpable allografts from EpiC (black) and CRC (gray) cell cultures. ${ }^{*} P<0.05$, log-rank. (B) Bar graphs illustrating the percentage of injected sites

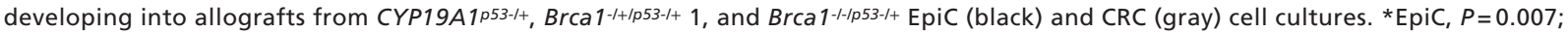
$* *$ CRC, $P=0.02$, CYP19A 1 $153-1++$ compared with Brca 1-1/1053-1+, Fisher's exact test. (C) Representative H\&E images of allografts that developed

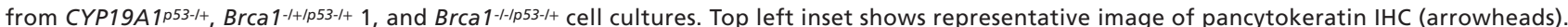
Bottom left inset shows representative magnification of H\&E image. (D) Time course of tumor size development for all injected sites that developed into allografts from EpiC (top, black lines) and CRC (bottom, gray lines) cell cultures. (E) Images of Cre (150 bp) and Actb (Actin) (250 bp) detection by RT-PCR (AlloBrca 1-1/p53-l+ CRC_1B). Markers (M) and NTC, no template-negative control shown from same gels. (F) Images showing the presence of Brca1 with exon 11 deletion product $(600 \mathrm{bp})$ in AlloBrca 1-1/p53-1+ CRC_2A but absent in WT and AlloCYP19A1 $553-1+$ CRC 6C-negative controls and Actb (Actin) $(250 \mathrm{bp}$ ) detection by RT-PCR from the same gels with Markers (M).

(G) Images of Cre ( $150 \mathrm{bp}$ ) and Actb (Actin) $(250 \mathrm{bp})$ detection by PCR of DNA from mammary epithelial cells secondarily grown in EpiC from AlloBrca 1-1/p53-/+ EpiC. Markers (M) shown from the same gels. (H) Images of CYP19A1 (150 bp) and Actb (Actin) (250 bp) detection by PCR of DNA from AlloCYP19A1 1533-l+ CRC_6C with WT-negative control. Markers (M) shown from the same gels. Thin lines between gel images indicate lanes taken from same gel. (I) Image showing normalized read coverage across the MMTV-Cre transgene viewed through the Integrative Genomics Viewer (IGV) from AlloBrca ${ }^{-1 / 1053-/+}$ EpiC_5A compared with background negative control WT mammary gland. (J) Representative IHC images of NIH3T3 fibroblasts as positive (arrowhead) and negative (no primary antibody) controls for CD140A/PDGFRA antibody. (K) Representative IHC images of allografts showing detection of CD140A/PDGFRA-positive fibroblasts (arrowheads). H\&E and IHC images taken at $40 x$. Size bars $=10 \mu \mathrm{M}$. 
Table 2 Allograft development and histology.

\begin{tabular}{|c|c|c|c|c|}
\hline Injected cell genotype & Mouse ID/site & Growth & Allograft identifier/RNAseq & Allograft histopathology \\
\hline \multirow[t]{8}{*}{ CYP19A1p53-1+ CRC } & B206 MG-A & No & & \\
\hline & B206 MG-C & Yes & AlloCYP19A1p53-/+ CRC_6C & $\begin{array}{l}\text { Undifferentiated } \\
\text { adenocarcinoma }\end{array}$ \\
\hline & B207 MG-A & No & & \\
\hline & B207 MG-C & No & & \\
\hline & B208 MG-A & No & & \\
\hline & B208 MG-C & No & & \\
\hline & B209 MG-A & No & & \\
\hline & B209 MG-C & No & & \\
\hline \multirow[t]{8}{*}{ CYP19A1p53-/+ EpiC } & B206 MG-B & No & & \\
\hline & B206 MG-D & No & & \\
\hline & B207 MG-B & Yes & AlloCYP19A1p53-/+ EpiC_7B & $\begin{array}{l}\text { Undifferentiated } \\
\text { adenocarcinoma with } \\
\text { spindloid/sarcomatoid } \\
\text { features }\end{array}$ \\
\hline & B207 MG-D & No & & \\
\hline & B208 MG-B & No & & \\
\hline & B208 MG-D & No & & \\
\hline & B209 MG-B & Yes & & $\begin{array}{l}\text { Undifferentiated } \\
\text { adenocarcinoma }\end{array}$ \\
\hline & B209 MG-D & No & & \\
\hline \multirow[t]{8}{*}{ Brca 1-/+/p53-/+ CRC } & B210 MG-A & No & & \\
\hline & B210 MG-B & Yes & AlloBrca1-1+/p53-/+ CRC_10B & $\begin{array}{l}\text { Spindloid/sarcomatoid } \\
\text { carcinoma with foci of } \\
\text { adenocarcinoma }\end{array}$ \\
\hline & B210 MG-C & Yes & AlloBrca1-1+/p53-/+ CRC_10C & $\begin{array}{l}\text { Spindloid/sarcomatoid } \\
\text { carcinoma }\end{array}$ \\
\hline & B210 MG-D & No & & \\
\hline & B211 MG-A & No & & \\
\hline & B211 MG-B & No & & \\
\hline & B211 MG-C & Yes & AlloBrca1-1+/p53-/+ CRC_11C & $\begin{array}{l}\text { Undifferentiated } \\
\text { adenocarcinoma }\end{array}$ \\
\hline & B211 MG-D & No & & \\
\hline \multirow[t]{7}{*}{ Brca 1-1+/p53-/+ EpiC } & B204 MG-A & No & & \\
\hline & B204 MG-B & Yes & & $\begin{array}{l}\text { Spindloid/sarcomatoid } \\
\text { carcinoma with foci of } \\
\text { undifferentiated } \\
\text { adenocarcinoma }\end{array}$ \\
\hline & B204 MG-C & Yes & AlloBrca1-/+/p53-/+ EpiC_4C & $\begin{array}{l}\text { Spindloid/sarcomatoid } \\
\text { carcinoma with foci of } \\
\text { undifferentiated } \\
\text { adenocarcinoma }\end{array}$ \\
\hline & B204 MG-D & No & & \\
\hline & B205 MG-A & Yes & AlloBrca1-1+/p53-/+ EpiC_5A & $\begin{array}{l}\text { Undifferentiated } \\
\text { adenocarcinoma with } \\
\text { spindloid/sarcomatoid } \\
\text { features }\end{array}$ \\
\hline & B205 MG-B & Yes & & $\begin{array}{l}\text { Undifferentiated } \\
\text { adenocarcinoma with } \\
\text { spindloid/sarcomatoid } \\
\text { features }\end{array}$ \\
\hline & B205 MG-C & Yes & & $\begin{array}{l}\text { Undifferentiated } \\
\text { adenocarcinoma with } \\
\text { spindloid/sarcomatoid } \\
\text { features }\end{array}$ \\
\hline
\end{tabular}

Original cancer histopathology

Undifferentiated

adenocarcinoma with

spindloid/sarcomatoid focus

Undifferentiated
adenocarcinoma

Undifferentiated
adenocarcinoma carcinoma with foci of enocarcinoma carcinoma undifferentiated adenocarcinoma carcinoma with foci of undifferentiated adenocarcinoma

Undifferentiated with ndifferentiated spindloid/sarcomatoid features 
Table 2 (Continued).

\begin{tabular}{|c|c|c|c|c|c|}
\hline Injected cell genotype & Mouse ID/site & Growth & Allograft identifier/RNAseq & Allograft histopathology & Original cancer histopathology \\
\hline & B205 MG-D & Yes & & $\begin{array}{l}\text { Undifferentiated } \\
\text { adenocarcinoma with } \\
\text { spindloid/sarcomatoid } \\
\text { features }\end{array}$ & \\
\hline \multirow[t]{12}{*}{ Brca 1-I-Ip53-/+ CRC } & B201 MG-A & Yes & & $\begin{array}{l}\text { Spindloid/sarcomatoid } \\
\text { carcinoma with foci of } \\
\text { undifferentiated } \\
\text { adenocarcinoma }\end{array}$ & $\begin{array}{l}\text { Undifferentiated } \\
\text { adenocarcinoma }\end{array}$ \\
\hline & B201 MG-B & Yes & AlloBrca 1--Ip53-/+ CRC_1 & $\begin{array}{l}\text { Spindloid/sarcomatoid } \\
\text { carcinoma }\end{array}$ & \\
\hline & B201 MG-C & Yes & & $\begin{array}{l}\text { Spindloid/sarcomatoid } \\
\text { carcinoma }\end{array}$ & \\
\hline & B201 MG-D & No & & & \\
\hline & B202 MG-A & Yes & AlloBrca 1--I/p53-/+ CRC_2 & $\begin{array}{l}\text { Spindloid/sarcomatoid } \\
\text { carcinoma with foci of } \\
\text { undifferentiated } \\
\text { adenocarcinoma }\end{array}$ & \\
\hline & B202 MG-B & Yes & & $\begin{array}{l}\text { Spindloid/sarcomatoid } \\
\text { carcinoma }\end{array}$ & \\
\hline & B202 MG-C & Yes & & $\begin{array}{l}\text { Spindloid/sarcomatoid } \\
\text { carcinoma }\end{array}$ & \\
\hline & B202 MG-D & No & & & \\
\hline & B212 MG-A & No & & & \\
\hline & B212 MG-B & Yes & AlloBrca 1-//p53-/+ CRC_12 & $\begin{array}{l}\text { Spindloid/sarcomatoid } \\
\text { carcinoma }\end{array}$ & \\
\hline & B212 MG-C & Yes & & $\begin{array}{l}\text { Spindloid/sarcomatoid } \\
\text { carcinoma }\end{array}$ & \\
\hline & B212 MG-D & Yes & & $\begin{array}{l}\text { Spindloid/sarcomatoid } \\
\text { carcinoma }\end{array}$ & \\
\hline \multirow[t]{8}{*}{ Brca 1--Ip53-I+ EpiC } & 689 MG-A & Yes & & $\begin{array}{l}\text { Spindloid/sarcomatoid } \\
\text { carcinoma }\end{array}$ & \\
\hline & 689 MG-B & Yes & & $\begin{array}{l}\text { Spindloid/sarcomatoid } \\
\text { carcinoma }\end{array}$ & \\
\hline & 689 MG-C & Yes & & $\begin{array}{l}\text { Spindloid/sarcomatoid } \\
\text { carcinoma }\end{array}$ & \\
\hline & 689 MG-D & Yes & & $\begin{array}{l}\text { Spindloid/sarcomatoid } \\
\text { carcinoma }\end{array}$ & \\
\hline & 692 MG-A & Yes & & $\begin{array}{l}\text { Spindloid/sarcomatoid } \\
\text { carcinoma }\end{array}$ & \\
\hline & 692 MG-B & Yes & & $\begin{array}{l}\text { Spindloid/sarcomatoid } \\
\text { carcinoma }\end{array}$ & \\
\hline & 692 MG-C & Yes & & $\begin{array}{l}\text { Spindloid/sarcomatoid } \\
\text { carcinoma }\end{array}$ & \\
\hline & 692 MG-D & Yes & & $\begin{array}{l}\text { Spindloid/sarcomatoid } \\
\text { carcinoma }\end{array}$ & \\
\hline
\end{tabular}

CRC, conditionally reprogrammed cell culture; EpiC, EpiCult-B mouse medium; ID, identification.

\section{RNAseq}

Total RNA was extracted from cell pellets $(n=12)$, mammary cancers $(n=2)$, and allografts $(n=10)$ using TRIzol (Thermo Fisher Scientific) followed by phase separation and precipitation using chloroform and isopropanol (Thermo Fisher Scientific); purified (RNeasy Plus Mini Kits; Qiagen); analyzed (Nanodrop, Agilent Bioanalyzer 2100; Agilent Technologies); converted to cDNA (SuperScript II; Invitrogen); sequencing libraries prepared (TruSeq RNA Sample Preparation Kit; Illumina, San Diego, CA, USA); and paired-5481 (P36), 9668 (P20), and 9740 (P21) $n=6$ or single-5504C/D (P7) $n=4$ and 3189 (P3) $n=2$ end sequencing performed (HiSeq 2000, Illumina, San Diego, CA, USA) with read quality determined (FastQC, http://www.bioinformatics.babraham.ac.uk/project/ fastqc); contaminated adaptor portions trimmed (Trim Galore, http://www.bioinformatics.babraham.ac.uk/ project/trim_galore) (See Gene Expression Omnibus

Published by Bioscientifica Ltd 
A

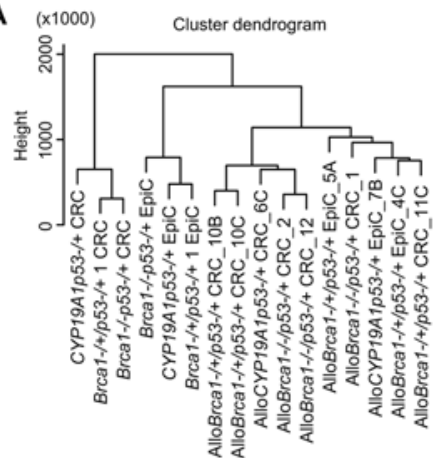

B
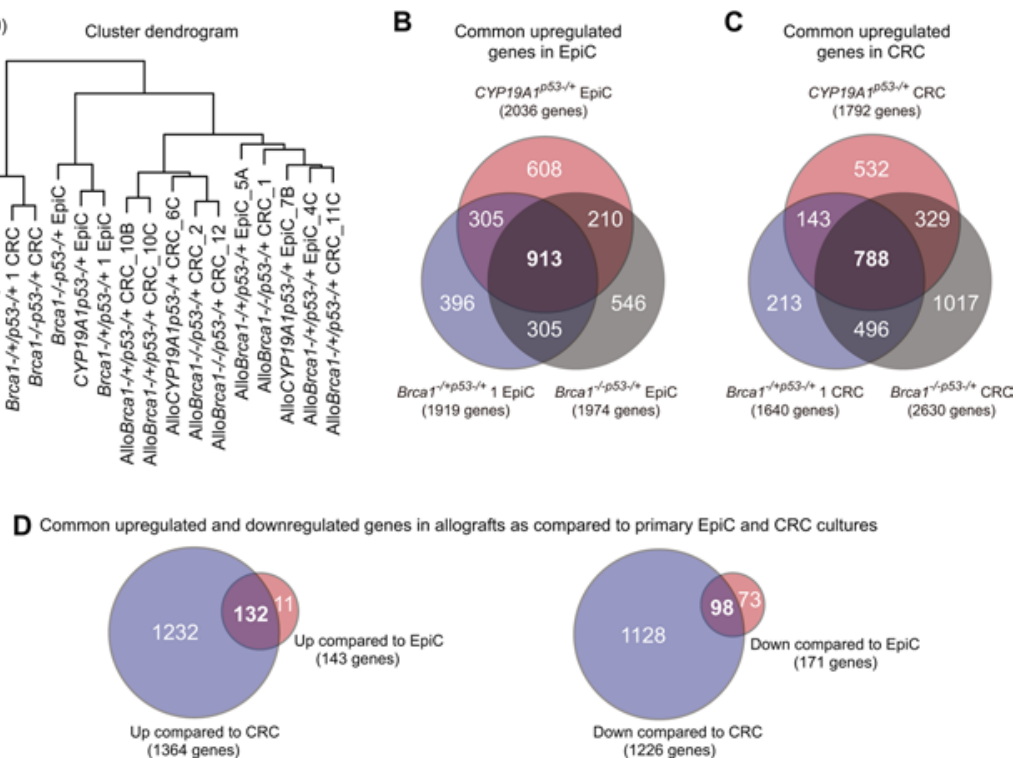

in allografts as compared to primary EpiC and CRC cultures

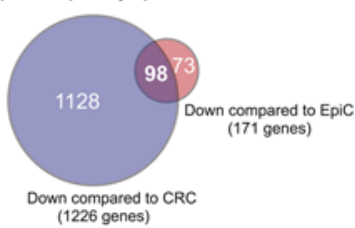

\begin{abstract}
Figure 3
Transcriptome characterization of EpiC and CRC cultures and allografts. (A) Dendrogram illustrating hierarchical clustering of transcriptomes from EpiC and CRC cultures and allografts. (B) Venn diagram illustrating overlaps between commonly upregulated significantly differentially expressed genes in EpiC-cultured CYP19A1p53-l+ (red), Brca 1-/+//153-l+ 1 (blue), and Brca 1-1/153-1+ (gray) primary mammary cancer cells compared with CRC culture. (C) Venn diagram illustrating the overlap between commonly upregulated significantly differentially expressed genes in CRC-cultured CYP19A1p53-1+ (red), Brca 1-///p53-/+ 1 (blue), and Brca 1-//p53-/+ (gray) primary mammary cancer cells compared with EpiC culture. (D) Venn diagrams illustrating the overlap between commonly upregulated and downregulated significantly differentially expressed genes in allografts compared with the respective primary cell cultures EpiC (red) and CRC (blue) from which they developed.
\end{abstract}

(GEO) database number GSE81212); and alignment to mouse reference genome (mm9) performed (Kim et al. 2013). Transcriptomes were assembled, transcript abundance estimated (FPKM: Fragments Per Kilobase of transcript per Million mapped reads), DEGs defined (statistically significant two-fold upregulation or 0.5-fold downregulation) (Cufflinks and Cuffdiff) (Trapnell et al. 2010, 2012), and mapped reads visualized (Integrative Genomics Viewer (IGV); Robinson et al. 2011, Thorvaldsdóttir et al. 2013). Statistically significant DEGs between individual pairs were identified to define genes that were commonly upregulated in EpiC $(n=913)$ vs CRC $(n=788)$ conditions. Allograft transcriptomes were compared with their respective cell culture transcriptome to identify significant DEGs. Genes that were commonly upregulated or downregulated in allografts compared with CRC (up: $n=1364$, down: $n=1226$ ) and EpiC (up: $n=143$, down: $n=171$ ) primary cultures were then compared to identify the subset of genes commonly upregulated or downregulated irrespective of primary culture/genotype (up: $n=132$, down $n=98$ ). Samples were clustered according to their gene expression profiles using the hclust function in $\mathrm{R}$ (http://www.R-project.org).

\section{Gene ontology, network analyses, and motif analysis}

Gene ontology (GO) was performed using Partek Genomics Suite 6.6, applying Fisher's Exact test, and restricting analyses to groups with more than two genes employing the default mapping method. Top 19 enrichment score categories were extracted for presentation. Hallmark gene sets (Molecular Signatures Database (MSigDB), http://www.broadinstitute.org/ gsea/msigdb/index.jsp) corresponding to commonly upregulated or downregulated DEGs were further analyzed by Pathway Studio to identify expression targets. DNA sequences in promoter regions $(-450 \mathrm{bp}$ - TSS - +50 bp) of DEGs upregulated in EpiC vs CRC were analyzed to identify transcription factor binding site (TFBS) motifs. Significantly enriched motifs $(P$ value $<0.001)$ were recognized utilizing the JASPAR motif database (http://jaspar.genereg.net/) (Kang et al. 2013). A second search algorithm, PSCAN (Zambelli et al. 2009), was used for further validation, and results were visualized as a heat map. Venn diagrams were designed by BioVenn (http://www.cmbi.ru.nl/cdd/ biovenn/) (Hulsen et al. 2008).

\section{Statistical analyses}

Two-tailed Fisher's exact test was used to compare the probabilities of primary culture establishment, allograft development, and correlations between genotypes and allograft histologies; log-rank test was used to test the identity of allograft development time course curves; and Kruskal-Wallis test with Dunn's multiple comparisons test was used to compare the proportion of fibroblasts in the allograft tissues (GraphPad Software). 
A

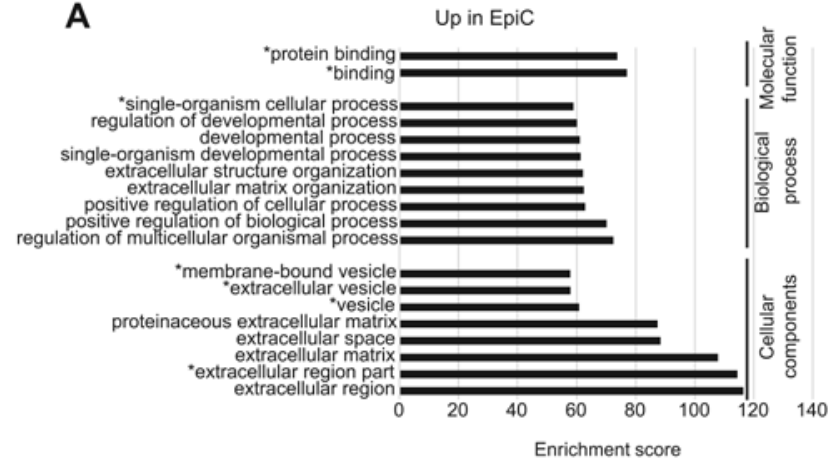

B

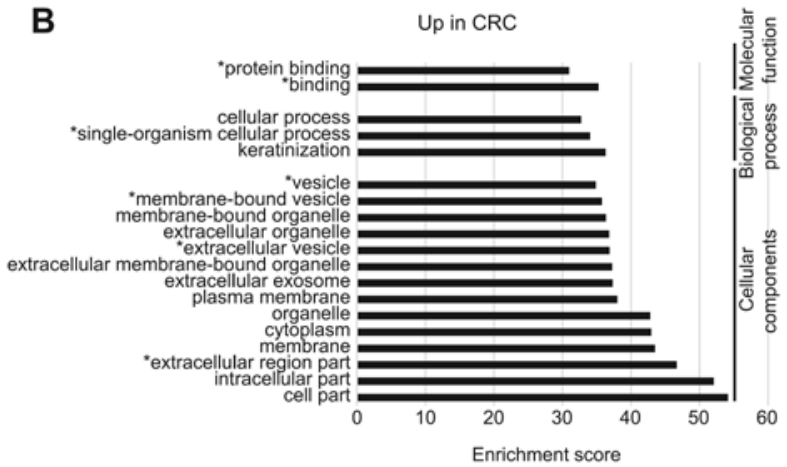

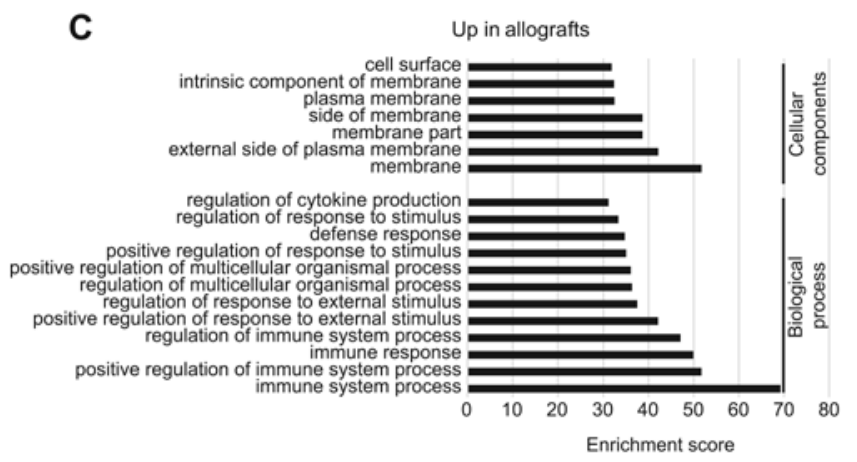

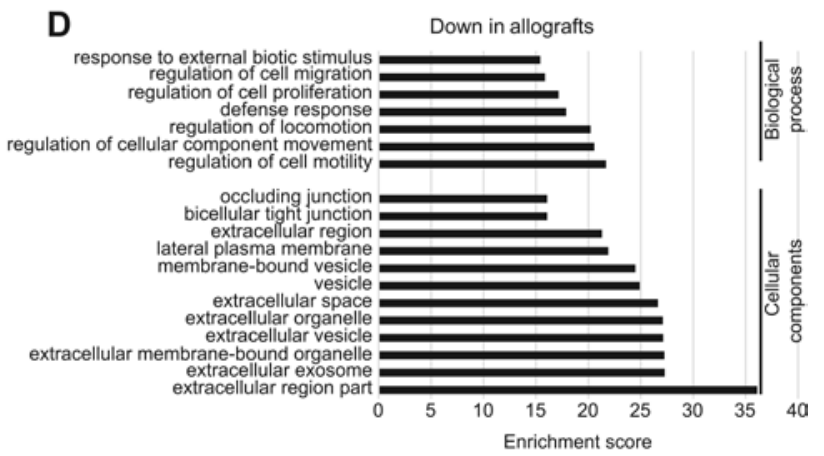

Figure 4

GO terms associated with commonly significantly differentially expressed genes under different culture and growth conditions. (A) Top $19 \mathrm{GO}$ or other functional terms associated with the 913 commonly significantly upregulated DEGs in EpiC cultures of mammary cancer cells from CYP19A1p53-1+, Brca 1-1/1/p53-1+ 1, and Brca 1-1/p53-/+ mice. (B) Top $19 \mathrm{GO}$ or other functional terms associated with the 788 commonly significantly upregulated DEGs in CRC cultures of mammary cancer cells from CYP19A1p53-1+ Brca 1-1/1/p53-1+ 1, and Brca 1-1/1053-1+ mice. (C) Top $19 \mathrm{GO}$ or other functional terms associated with the 132 commonly significantly upregulated DEGs in allografts of CYP19A1p53-1+, Brca 1-1/1/p53-1+ 1, and Brca 1-1/155-1+ mammary cancer cells compared with the respective EpiC and CRC primary cell cultures they developed from. (D) Top $19 \mathrm{GO}$ or other functional terms associated with the 98 commonly

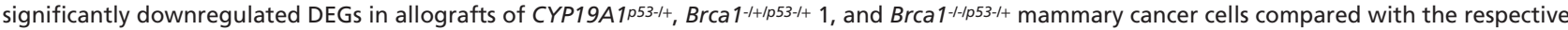
EpiC and CRC primary cell cultures they developed from. DEG, differentially expressed genes; GO, gene ontology.

\section{Results}

\section{Conditional reprogramming culture (CRC) conditions were more successful for initial establishment of primary cultures than EpiCult-B or DMEM}

CRC methodology was associated with a significantly higher likelihood of establishing primary cultures of mouse mammary epithelial cells (95\%) in comparison with EpiCult-B (EpiC) $(60 \%, P=0.02)$ and DMEM (35\%, $P=0.0003$ ) (Table 1). Doubling times were faster for CRC and EpiC compared with DMEM for both cancer and noncancer cells (Fig. 1A). Brca1 gene dosage did not affect the likelihood of prolonged passage of mammary cancer cells for either CRC or EpiC (Fig. 1B and Table 1) (Groeneveld 2012). Of the nine cancer cell cultures, eight initially established in either CRC or EpiC were successfully moved to DMEM (Table 1).

\section{Allografts derived from cells cultured under EpiC conditions formed more quickly than those from CRC-cultured cells}

Allograft formation was investigated using three paired sequentially passaged ( $>20$ ) CRC and EpiC primary triplenegative epithelial cancer cell cultures with different Brca1 gene dosages coupled with p53 haploinsufficiency. Palpable allografts developed significantly faster from EpiC compared with CRC cultures $(P<0.05$, log-rank, Fig. 2A). Loss of both Brca1 alleles significantly increased the probability of allograft formation (EpiC, $P=0.007$; CRC, $P=0.02$; Fisher's Exact; Fig. 2B) and appearance of uniform spindloid/sarcomatoid histology ( $P=0.04$; Fisher's Exact; Fig. 2C and Table 2). Tumorigenicity occurred earlier and was more variable from EpiC compared with CRC cultures (Fig. 2D).

Published by Bioscientifica Ltd 
Table 3 Hallmark gene sets identified from differentially regulated genes in different culture and growth conditions.

\section{Epic}

\section{CRC}

(A) Top ten hallmark gene sets identified in DEGs upregulated in EpiC compared with CRC cultures

\section{EPITHELIAL_MESENCHYMAL_TRANSITION P53_PATHWAY}

TNFA_SIGNALING_VIA_NFKB

HYPOXIA

INFLAMMATORY_RESPONSE

ESTROGEN_RESPONSE_EARLY

APICAL_JUNCTION

KRAS_SIGNALING_UP

ESTROGEN_RESPONSE_LATE

COAGULATION

IL6_JAK_STAT3_SINGNALING

APOPTOSIS

INTERFERON_GAMMA_RESPONSE

UV_RESPONSE_DN

KRAS SIGNALING DN

APICAL_SURFACE

KRAS_SIGNALING_UP

PI3K AKT MTOR SIGNALING

MYOGENESIS

APOPTOSIS

(B) All hallmark gene sets identified in DEGs upregulated in allografts compared with EpiC and CRC cultures they were derived from ALLOGRAFT_REJECTION

KRAS_SIGNALING_UP

ALLOGRAFT_REJECTION

KRAS_SIGNALING_UP

INTERFERON_GAMMA_RESPONSE

COMPLEMENT

INFLAMMATORY_RESPONSE

INTERFERON_GAMMA_RESPONSE

COMPLEMENT

INFLAMMATORY_RESPONSE

EPITHELIAL_ MESENCHYMAL_TRANSITION

(C) All hallmark gene sets identified in DEGs upregulated in original cancers compared with EpiC and CRC cultures derived from them

KRAS_SIGNALING_UP

ALLOGRAFT_REJECTION

ALLOGRAFT_REJECTION

KRAS SIGNALING UP

INFLAMMATORY_RESPONSE

Hallmark gene sets unique to paired comparisons are given in bold.

Spindloid/sarcomatoid cancers demonstrated cytokeratin expression, consistent with epithelial derivation (Fig. 2C, insets). Studies of nucleic acids extracted from allograft tissue and/or secondarily cultured cells confirmed the presence of GEMM modifications (Fig. 2E, F, G, H and I). The proportion of fibroblasts compared with cancer cells was low in allografts (CYP19A1p53-/+ CRC: $1.5 \pm 0$, CYP19A1p53-/+

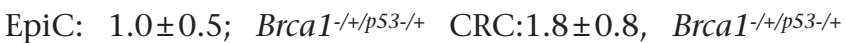
EpiC: $\quad 2.3 \pm 0.6^{*} ; \quad$ Brca1-1/p53-/+ $\quad$ CRC: $0.9 \pm 0.4$, Brca1-//p53-/+ EpiC: 0.6 $\pm 0.1^{*}$ CD140A/PDGFRA-positive fibroblasts per $40 \times$ high-power field; values given as mean \pm s.E.M., $\quad{ }^{*} P<0.05$, Kruskal-Wallis test, Dunn's multiple comparisons test) (Fig. 2J and K).

\section{CRC and EpiC in vitro cultures demonstrated dissimilar gene expression patterns with in vivo allograft gene expression more similar to EpiC than CRC}

To identify pathways preferentially activated under the different growth conditions, RNAseq was used to characterize transcriptomes of these three paired cell cultures and derived allografts. Hierarchical clustering revealed that culture and growth condition, rather than genetic identity, was the primary determinant of transcriptome similarity. Commonly statistically significantly upregulated DEGs were defined for both EpiC (913) and CRC (788) cultures, independent of genotype
(Fig. 3A, B and C). GO enrichment analyses were performed on these two DEG sets to delineate biological processes and cellular component categories distinctly enriched under the two different culture conditions. More than half (63\%) of the top categories identified for each culture condition were unique (Fig. 4A and B). Developmental and organismal biological processes were exclusive to EpiC and keratinization to CRC. MSigDB was queried to identify unique hallmark gene sets associated with the DEGs. Epithelial_Mesenchymal_Transition (EMT) was the most significant hallmark gene set for upregulated DEGs in EpiC and P53_Pathway for upregulated DEGs in CRC (Table 3A).

Hierarchical clustering demonstrated that EpiCand CRC-derived allografts grouped together within the same larger branch as EpiC (Fig. 3A). To investigate how allograft gene expression patterns differed from cell culture source, DEGs commonly upregulated and downregulated in EpiC- and CRC-derived allografts were compared with their parent cultures. CRC-derived allografts showed a log higher number of DEGs (1364 upregulated and 1226 downregulated) compared with EpiC-derived allografts (143 and 171) (Fig. 3D). The majority of upregulated (92\%) and downregulated (57\%) DEGs identified in EpiC-derived allografts were also changed in CRC-derived allografts. GO enrichment analyses demonstrated that all of the top categories

Published by Bioscientifica Ltd. 
A

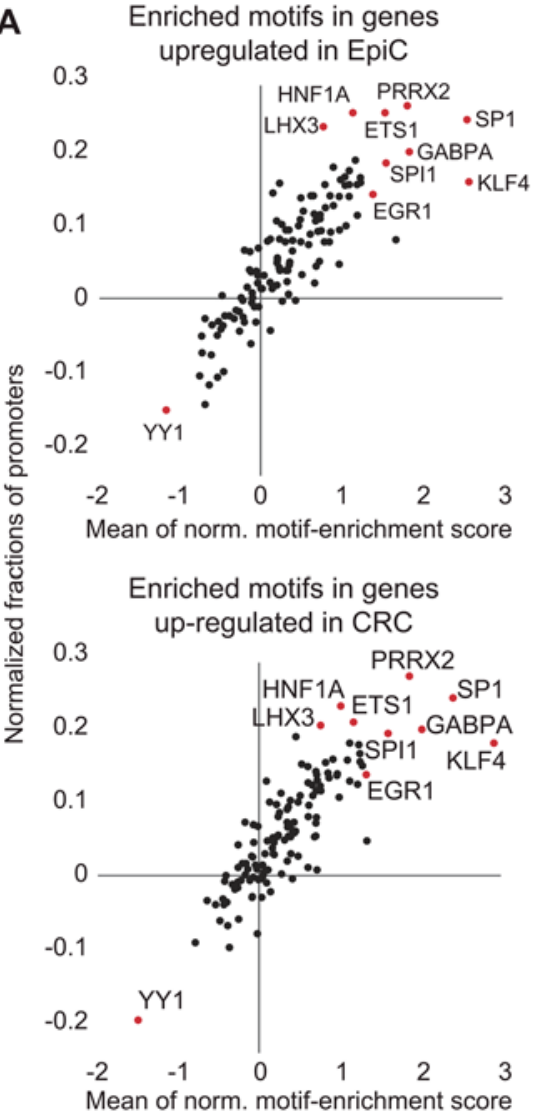

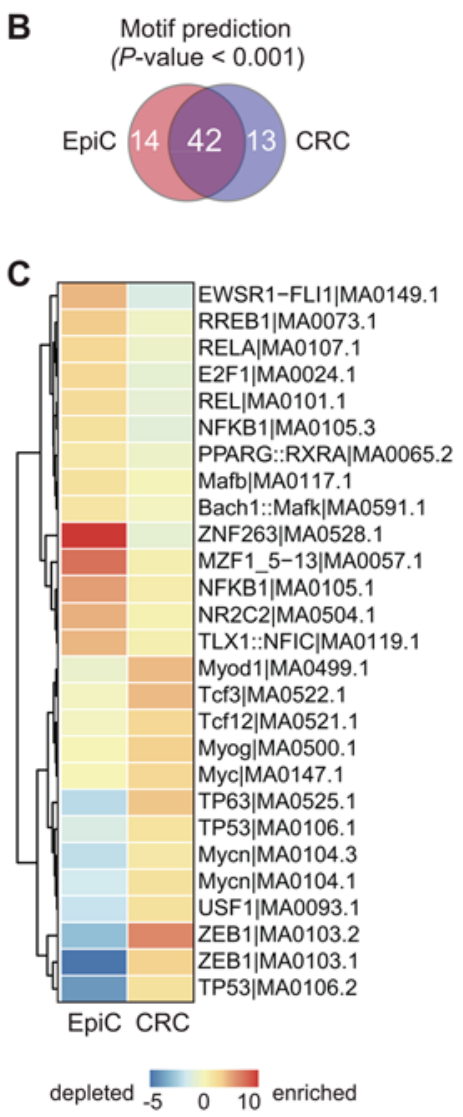
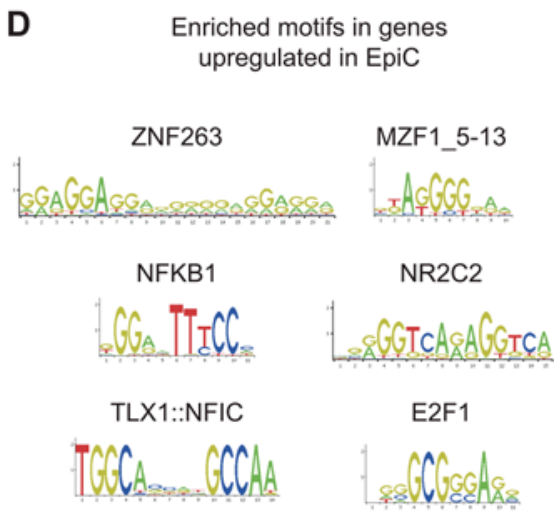

Enriched motifs in genes up-regulated in CRC

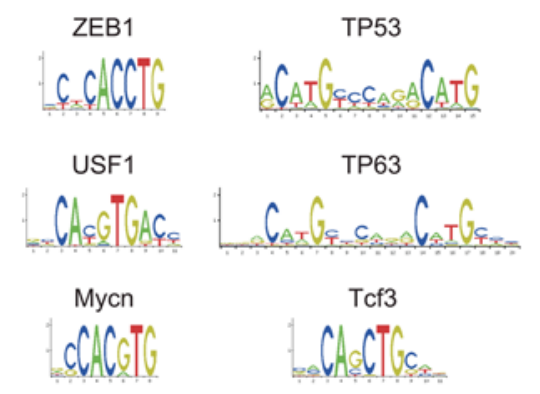

Figure 5

Transcription factor binding sites associated with commonly significantly differentially expressed genes under different culture conditions. (A) Scatter plots of transcription factor binding sites (TFBS) enriched motifs identified in DEGs significantly upregulated in EpiC and CRC cultures. All motif occurrences in the DEGs were calculated using the MOODS algorithm with the 130 position-frequency matrices available on the JASPAR website $(P$ value $<0.001)$. The $x$-axis and $y$-axis indicate the mean average of normalized motif enrichment scores and normalized fractions of promoters presented on the $y$-axis, respectively. Each dot represents a single TFBS and red dots show significantly associated co-TFBSs (normalized proportion $>0.2$ and average of normalized motif enrichment score $>1.5$ ). Note that many of the same TFBS are enriched or depleted under both conditions. HNF1A, hepatocyte nuclear factor 1 homeobox A; PRRX2, paired related homeobox 2; LHX3, LIM homeobox 3; ETS1, V-Ets avian erythroblastosis virus E26 oncogene homolog 1; SP1, Sp1 transcription factor; GABPA, GA binding protein transcription factor, alpha subunit $60 \mathrm{kDa}$; SPI1, Spi-1 proto-oncogene; KLF4, Kruppel-like factor 4; EGR1, early growth response 1. (B) Venn diagram illustrating the overlap between TFBS significantly enriched in DEGs commonly upregulated in EpiC (red) compared with CRC (blue) cultures. (C) Heat map illustrating relative levels of enrichment vs depletion of the 27 TFBS identified as unique to EpiC (14 TFBS) and CRC (13 TFBS) cultures. EWSR1, EWS RNA-binding protein 1; FLI1, friend leukemia integration 1; RREB1, Ras-responsive element binding protein 1; RELA, V-Rel avian reticuloendotheliosis viral oncogene homolog A; E2F1, E2F transcription factor 1; Rel: V-Rel avian reticuloendotheliosis viral oncogene homolog; NFKB1, nuclear factor of kappa light polypeptide gene enhancer in B-cells 1; PPARG, peroxisome proliferator-activated receptor gamma; Mafb, V-Maf avian musculoaponeurotic fibrosarcoma oncogene homolog B; Bach1, BTB and CNC homology 1, basic leucine zipper transcription factor 1; ZNF, zinc finger protein; MZF1, myeloid zinc finger 1; NR2C2, nuclear receptor subfamily 2, group $C$, member 2; TLX1, T-cell leukemia homeobox 1; NFICL nuclear factor I/C (CCAAT-binding transcription factor). MyoD, myogenic differentiation; Tcf3, transcription factor 3; Tcf12; transcription factor 12; Myog, myogenin (myogenic factor 4); Myc, V-Myc avian myelocytomatosis viral oncogene homolog; TP63, transforming protein 63; TP53, transforming protein 53; Mycn, V-Myc avian myelocytomatosis viral oncogene neuroblastoma derived homolog; USF1, upstream transcription factor 1; ZEB1, zinc finger E-box binding homeobox 1. (D) Visualization of the six most enriched TFBS motifs identified from DEGs significantly upregulated under EpiC and CRC conditions. TFBS for ZNF263 (also known as ZSCAN12), MZF1_5-13, NFKB1, NR2C2, TLX1::NFIC, and E2F1 were uniquely enriched in genes upregulated under EpiC conditions whereas TFBS for ZEB1, TP53, USF1, TP63, Mycn, and Tcf3 were uniquely enriched under CRC conditions. Norm, normalized.

identified in the upregulated and downregulated DEGs were unique (Fig. 4C and D). Immune biological processes were exclusive to upregulated DEGs in allografts and motility-related biological processes to the downregulated DEGs. MSigDB analyses demonstrated that the EMT gene set was uniquely identified in DEGs upregulated in CRCderived allografts (Table 3B) signifying EMT as a process occurring during allograft formation. This was compatible with the spindloid/sarcomatoid histology the majority of the allografts demonstrated, independent of the culture

Published by Bioscientifica Ltd. 
A

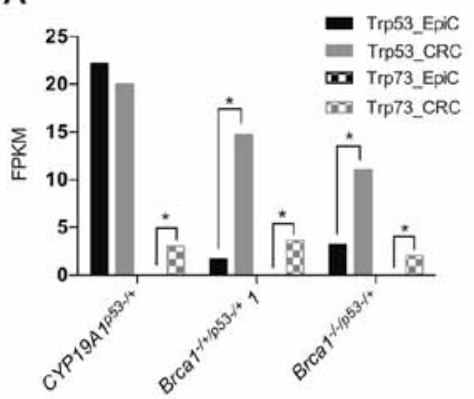

C

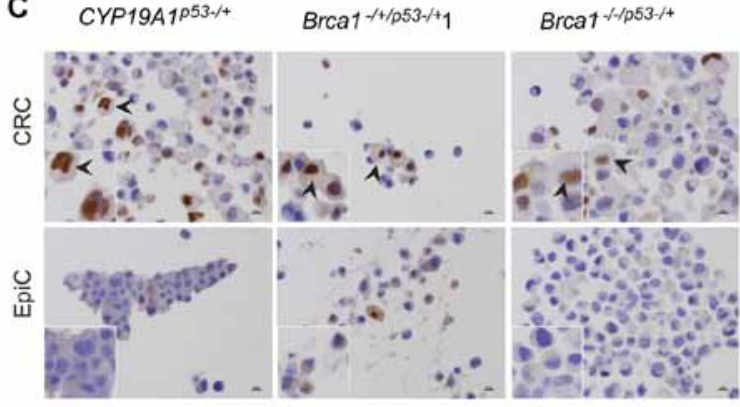

B

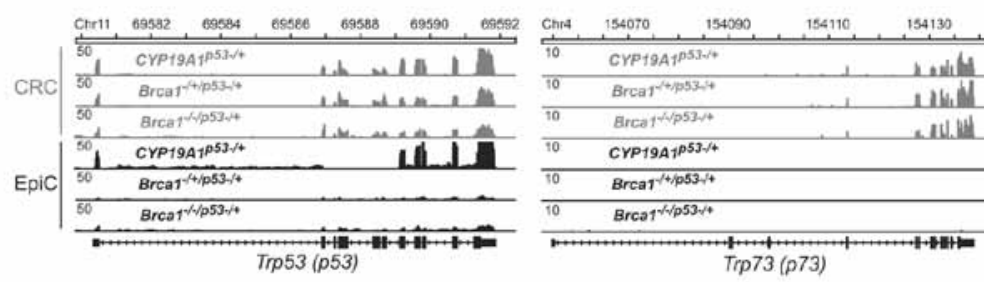

E

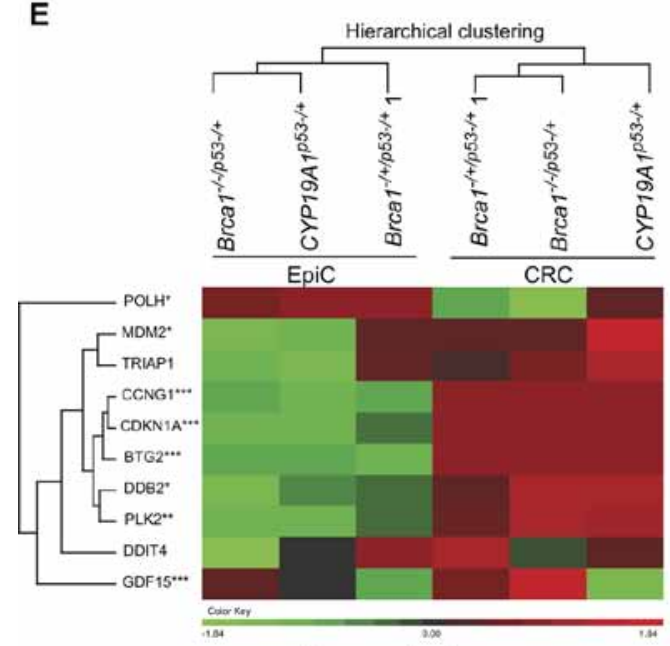

Prosurvival genes
D CYP19A1 $153-\gamma^{+*}$

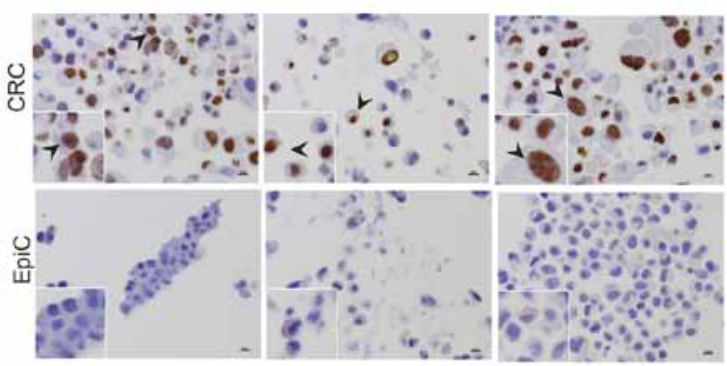

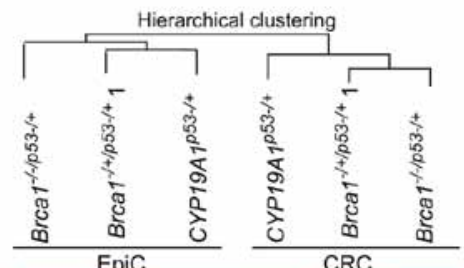
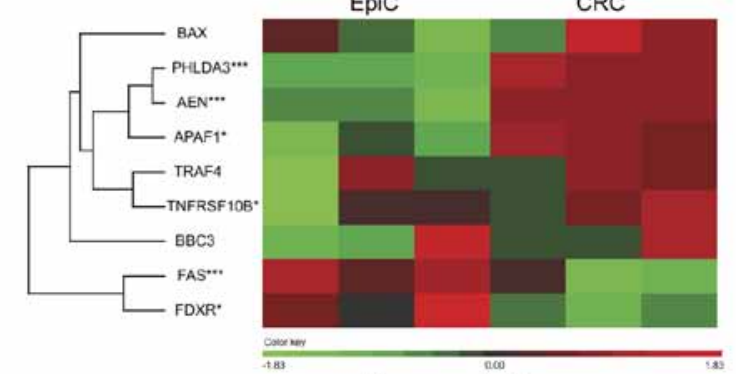

Proapoptotic genes

\section{Figure 6}

Expression levels of p53 family members were higher under CRC compared with EpiC culture conditions. (A) Bar graphs illustrating relative FPKM (Fragments Per Kilobase of transcript per Million mapped) reads of Trp53 and Trp73 in EpiC (black) and CRC (gray) in primary CYP19A1p53-/+, Brca1//+/p53-/+ 1, and Brca 1--1p53-I+ cancer cell cultures. *P<0.05, Cuffdiff_pval. (B) Images showing normalized read coverage across the Trp53 and Trp73 loci viewed through the Integrative Genomics Viewer from CYP19A1p53-/+, Brca 1-1+/p53-1+ 1, and Brca 1-//p53-/+ EpiC (black) and CRC (gray) cultures. (C) Representative images of immunohistochemistry (IHC) for p53 in CYP19A1p53-1+, Brca 1-1+/p53-1+ 1, and Brca 1--1p53-I+ cell pellets prepared from EpiC and CRC cultures. Insets at the bottom left show magnified images of cells indicated by arrows in larger images. Black arrows indicate representative cells with detection of nuclear-localized p53. IHC images taken at 40x. Size bars $=10 \mu \mathrm{M}$. (D) Representative images of immunohistochemistry (IHC) for p63 in CYP19A1p53-/+, Brca 1-1+/p53-/+ 1, and Brca 1-1/p53-/+ cell pellets prepared from EpiC and CRC cultures. Insets at the bottom left show magnified images of cells indicated by arrows in larger images. Black arrows indicate representative cells with detection of nuclear-localized p63. IHC images taken at $40 \times$. Size bars $=10 \mu \mathrm{M}$. (E) Dendrograms and heat maps of unsupervised hierarchical clustering of FPKM values of p53-regulated prosurvival and proapoptotic genes from EpiC and CRC CYP19A1 155-/+ , Brca 1-/+/p53-/+ 1, and Brca1-/-/p53-/+ cultures. POLH, polymerase (DNA directed), Eta. MDM2: MDM2 proto-oncogene, E3 ubiquitin protein ligase. TRIAP1, TP53-regulated inhibitor of apoptosis 1. CCNG1, cyclin G1. CDKN1A, cyclin-dependent kinase inhibitor 1A (P21, Cip1). BTG2, BTG family, member 2. DDB2, damage-specific DNA binding protein 2, 48 kDa. PLK, polo-like kinase. DDIT4, DNA-damage-inducible transcript 4. GDF, growth differentiation factor. BAX, BCL2-associated X protein. PHLDA3, pleckstrin homology-like domain, family A, member 3. AEN, apoptosis enhancing nuclease. APAF1, apoptotic peptidase activating factor 1. TRAF4, tissue necrosis factor receptor-associated factor 4 . TNFRSF, tumor necrosis factor receptor superfamily. $\mathrm{BBC} 3, \mathrm{BCL} 2$ binding component 3. FAS, Fas cell surface death receptor. FDXR, ferredoxin reductase. *One EpiC/CRC pair, **Two EpiC/CRC pairs, ***Three EpiC/CRC pairs, $P<0.05$, Cuffdiff_pval. 
condition they were derived from. Immunologically related gene sets (Allograft_Rejection, Interferon_Gamma Response, Complement, and Inflammatory_Response) were common to upregulated DEGs for both EpiC- and CRC-derived allografts (Table 3B).

To explore whether distinct sets of transcription factors (TF) might be responsible for the significantly different DEGs between EpiC and CRC, transcription factor binding site (TFBS) motifs enriched and depleted in the two datasets were examined using the JASPAR database (Kang et al. 2013) and PSCAN (Zambelli et al. 2009). The JASPAR database demonstrated that the unique sets of DEGs contained many commonly enriched/ depleted TFBS (Fig. 5A). Similarly, PSCAN demonstrated that the majority of enriched TFBS were shared (61\%) but also identified TFBS relatively enriched under the two culture conditions (Fig. 5B, C and D). EpiC-enriched TFBS included NFKB1, RELA, and E2F1 sites, TFs positively linked to EMT, the most significant hallmark gene sets. However, the TFBS for another EMT-linked gene, ZEB1, was found relatively enriched under CRC, so there was no perfect correlation between enriched TFBS and hallmark gene sets. CRC-enriched unique TFBS included TP53 and TP63, connecting with the P53_Pathway being the most significant hallmark gene set for CRC.

\section{Corroboration of $\mathrm{p} 53$ pathway changes and variance in EMT-related gene expression}

The P53_Pathway and Epithelial_Mesenchymal_Transition were selected for focused study because they were the two most significant hallmark gene sets and enriched TFBS corresponding to each category were identified. Fragments Per Kilobase of transcript per Million mapped reads (FPKM) were significantly higher for Trp53 and Trp73 under CRC compared with EpiC conditions $(P<0.05)$ (Fig. 6A). Mapped reads were confirmed as corresponding appropriately to the $\operatorname{Tr} p 53$ and $\operatorname{Trp} 73$ exon structures (Fig. 6B). Trp63 also demonstrates higher FPKM values under CRC compared with EpiC in these cells (Assefnia et al. 2014), consistent with the reports from others reporting CRC conditions upregulating p63 expression (Suprynowicz et al. 2012, Chapman et al. 2014). Immunohistochemical staining intensity, relative numbers of cells staining, and nuclear localization of p53 and p63 were higher in CRC compared with EpiCcultured cells (Fig. 6C). Hierarchical clustering revealed that samples grouped by culture condition rather than genotype when examining relative expression levels of defined p53-regulated prosurvival and proapoptotic genes
(Allen et al. 2014), consistent with higher activation levels of p53 family members under CRC conditions (Fig. 6D).

A similar approach was taken for examination of EMTrelated genes. Allograft samples were included because Epithelial_Mesenchymal_Transition was a significant hallmark gene set identified when CRC-derived allograft transcriptomes were compared with those of their parent cultures (Table 3B). Hierarchical clustering of defined EMT-related genes separated groups by culture and growth condition compared with genotype with allografts clustered more closely to EpiC compared with CRC cultures (Fig. 7A). Of note, Zeb1 and Zeb2 FPKM levels, TFs that bind TFBS ZEB1 (Fig. 5D), were significantly lower in CRC compared with EpiC conditions (Fig. 7A). Because the TGF- $\beta$ pathway is a defined activator of EMT (Gonzalez \& Medici 2014) and previously reported to be downregulated under CRC conditions (Ligaba et al. 2015), FPKM levels of $T g f b 1,2$, and 3 and Tgfbr1, 2, and 3 were specifically included (Fig. 7A). Tgfbr3 FPKM values were significantly higher under EpiC compared with CRC conditions in all three paired cultures, whereas $T g f b 3$ was higher in two pairs and $T g f b 2$ and $T g f b r 1$ in one (Fig. 7A and B). Tgfbr3 reads mapped appropriately to Tgfbr3 exon structure (Fig. 7C). Intensity of membrane-localized staining and numbers of cells stained for TGFBR3 using immunohistochemistry were higher in cells cultured under EpiC compared with CRC conditions (Fig. 7D).

\section{Expression of mammary epithelial cell differentiation genes was not retained in allografts}

Genes linked to mammary gland differentiation in vivo were selected for specific examination because retention of mammary epithelial cell differentiation-related gene expression in primary culture and allografts is of interest to mammary gland biologists and breast cancer researchers. Hierarchical clustering indicated that for all but one culture (EpiC: Brca1- $/$ p53-/+) the number of differentiation-related genes with higher FPKM values was greatest under CRC conditions followed by EpiC and then allografts (Fig. 8A). Keratin (K) genes expressed in vivo in human breast cancers $(\mathrm{K} 5,6,7,8,14,18,19)$ and normal differentiated luminal $(\mathrm{K} 7,8,18,19)$ and basal $(\mathrm{K} 5,6,14,17)$ mammary epithelial cells were included in the analyses (Taylor-Papadimitriou et al. 1989, Trask et al. 1990, Grimm et al. 2006, Livasy et al. 2006, Shao et al. 2012, Kang et al. 2014, Visvader \& Stingl 2014). Overall keratin FPKM levels were highest under CRC conditions, consistent with higher intensity of membrane-localized staining and numbers of cells staining for pan-cytokeratin (Fig. 8B) and identification of

Published by Bioscientifica Ltd 


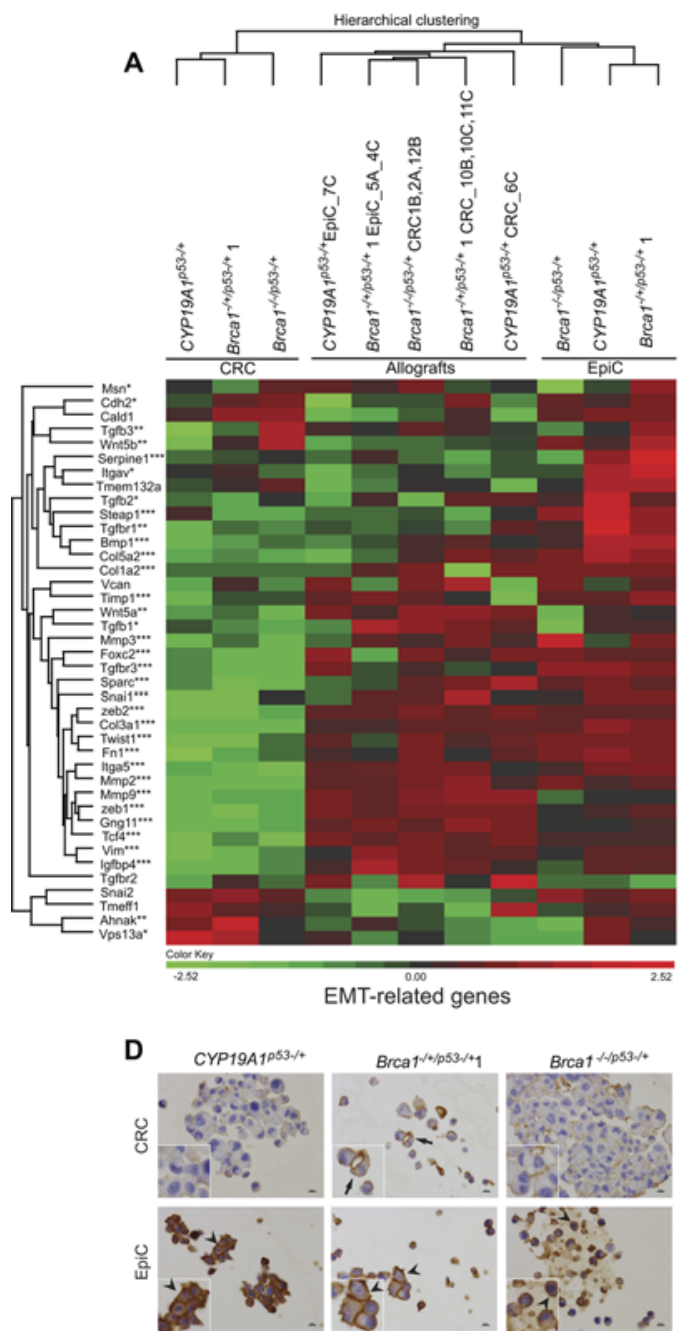

B

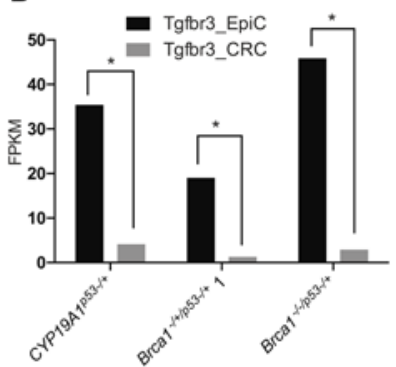

C

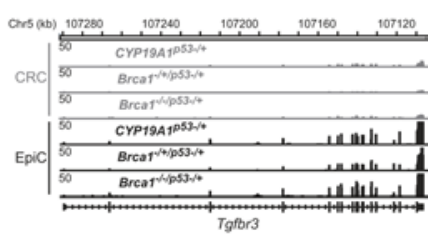

Figure 7

Expression levels of epithelial-mesenchymal transition genes were higher under EpiC compared with CRC culture conditions.

(A) Dendrogram and heat map of unsupervised hierarchical clustering of FPKM values of epithelial-mesenchymal transition (EMT)-related

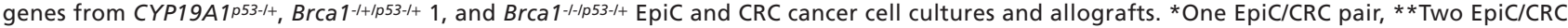
pairs, ***Three EpiC/CRC pairs, $P<0.05$, Cuffdiff_pval. Msn, Moesin. Cdh2, cadherin 2, type 1. Cald1, Caldesmon 1. Tgfb3, transforming growth factor beta 3. Wnt5b: Wnt5b: wingless-type MMTV integration site family, Member 5B. Serpine1, serpin peptidase inhibitor, clade E (Nexin, plasminogen activator inhibitor type 1), member 1. Itgav, integrin, alpha V. Tmem132a, transmembrane protein 132A. Tgfb3, transforming growth factor beta 3. Steap, six-transmembrane epithelial antigen of prostate 2. Tgfbr1, transforming growth factor beta receptor 1. Bmp1, bone morphogenetic protein 1. Col5a2, collagen, type V, alpha 2. Col1a2, collagen, type I, alpha 2. Vcan, versican. Timp1, TIMP metallopeptidase inhibitor 1. Wnt5a, wingless-type MMTV integration site family, member 5A. Tgfb1, transforming growth factor beta 1. Mmp3, matrix metallopeptidase 3. Foxc2, forkhead box C2. Tgfbr3, transforming growth factor beta receptor 3. Sparc, secreted protein, acidic, cysteine-rich (osteonectin). Snai1, snail family zinc finger 1. Zeb2, zinc finger E-box binding homeobox 2. Col3a1, collagen, type III, alpha 1. Twist1, twist family BHLH transcription factor 1. Fn1, fibronectin 1. Itga5, integrin, alpha 5 (fibronectin receptor, alpha polypeptide). Mmp2, matrix metallopeptidase 2. Mmp9, matrix metallopeptidase 9. Zeb1, zinc finger E-box binding homeobox 1. Gng 1, guanine nucleotide binding protein (G Protein), gamma 11. Tcf4, transcription factor 4. Vim, vimentin. Igfbp4, insulin-like growth factor binding protein 4. Tgfbr2, transforming growth factor beta receptor 2. Snai2, snail family zinc finger 2. Tmeff1, transmembrane protein with EGF-like and two follistatin-like domains 1 . Ahnak, AHNAK nucleoprotein. Vps13a, vacuolar protein sorting 13 homolog A. (B) Bar graphs illustrating relative FPKM (Fragments Per Kilobase of

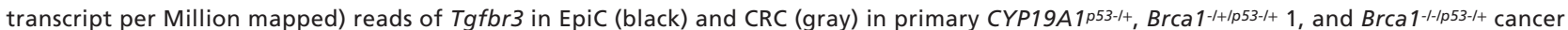
cell cultures. ${ }^{*} P<0.05$, Cuffdiff_pval. (C) Images showing normalized read coverage across the Tgfbr3 locus viewed through the Integrative Genomics Viewer from CYP19A1p53-/+, Brca 1-/+/p53-1+ 1, and Brca 1-1//p53-l+ EpiC (black) and CRC (gray) cultures. (D) Representative images of

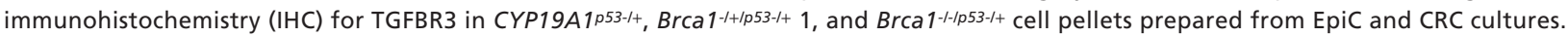
Insets at the bottom left show magnified images of cells indicated by arrows in larger images. Black arrows indicate representative cells with detection of membrane-localized TGFBR3. IHC images taken at 40x. Size bars $=10 \mu \mathrm{M}$. 
A
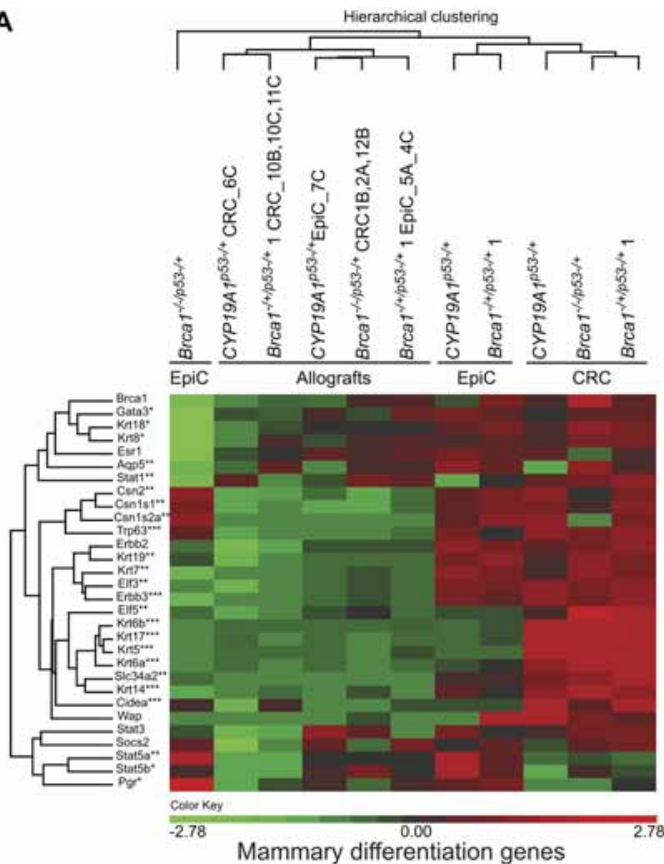

B

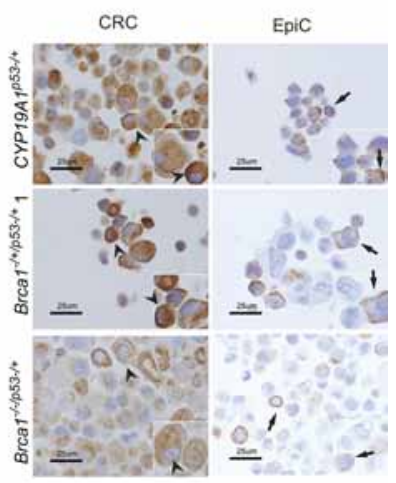

\section{Figure 8}

Relative expression levels of mammary epithelial cell differentiation genes in EpiC and CRC cultures and allografts. (A) Dendrogram and heat map of unsupervised hierarchical clustering of FPKM values of mammary epithelial cell differentiation-related genes from CYP19A1p53-1+, Brca 1///p53-/1+ 1, and Brca 1-1/1553-/+ EpiC and CRC cancer cell cultures and allografts. *One EpiC/CRC pair, $* *$ Two EpiC/CRC pairs, $* * *$ Three EpiC/CRC pairs, ${ }^{*} P<0.05$, Cuffdiff_pval. Brca1, breast cancer 1, early onset. Gata3, GATA binding protein 3. Krt18, keratin 18, type I. Krt8, keratin 8, type II. Esr1, estrogen receptor 1. Aqp5, aquaporin 5. Stat1, signal transducer and activator of transcription 1, $91 \mathrm{kDa}$. Csn2, casein beta. Csn1s1, casein alpha S1. Csn1s2a, casein alpha S2-like A, pseudogene. Trp63, tumor protein P63. Erbb2, Erb-B2 receptor tyrosine kinase 2. Krt19, keratin 19, type I. Krt7, keratin 7, type II. Elf3, E74-like factor 3 (Ets domain transcription factor, epithelial-specific). Erbb3, Erb-B2 receptor tyrosine kinase 3. Elf5, E74-like factor 5 (Ets domain transcription factor). Krt6b, keratin 6B, type II. Krt17, keratin 17, type I. Krt5, keratin 5, type II. Krt6a, keratin 6A, type II. Slc34a2, solute carrier family 34 (type II sodium/ phosphate co-transporter), member 2. Krt14, keratin 14, type I. Cidea, cell death-inducing DFFA-like effector A. Wap, whey acidic protein. Stat3, signal transducer and activator of transcription 3 (acute-phase response factor). Socs2, suppressor of cytokine signaling 2. Stat5a, signal transducer and activator of transcription 5A. Stat5b, signal transducer and activator of transcription 5B. Pgr, progesterone receptor. (B) Representative images of

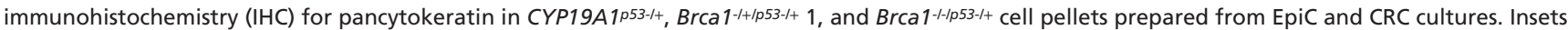
at the bottom right show magnified images of cells indicated by arrows in larger images. Black arrows indicate representative cells showing cytoskeletal localization. IHC images taken at 40x. Size bars $=10 \mu \mathrm{M}$.

keratinization as a unique GO-enriched biological process (Fig. 4B). Esr1 expression was not significantly altered by culture condition; however, Erbb3 was higher under CRC in all three pairs (Fig. 8A).

\section{Primary cells cultured for a limited number of passages under either condition maintained gene expression patterns that were not significantly different from source tissue}

We next determined whether shortening passage number $(P=7)$ reduced the number of significantly altered DEGs between the two culture conditions. Cells were isolated from two cancers that developed in the same mouse $\left(\mathrm{BrCa}^{-/+/ p 53-/+/ C Y P 19 A 1}\right)$. Transcriptomes were compared with each other as well as to the parent cancer from which the cells were derived. There was no clustering by culture or growth condition for EMT-related, mammary differentiation, or p53 pathway genes (Fig. 9A, B and C), and the magnitude of significantly different DEGs between each culture condition and the parent cancer were similar (Fig. 9D and E) even given the disparate cancer histologies (cancer 1: poorly differentiated adenocarcinoma; cancer 2: spindloid/sarcomatoid carcinoma) (Fig. 9F). The few commonly significantly upregulated or downregulated DEGs mapped to less than three hallmark gene sets (Allograft_Rejection, Kras_ Signaling_up, and Inflammatory_Response) (Table 3C). Normal wild-type mammary epithelial cells cultured for three passages before RNAseq analyses showed similar results with few statistically significant DEGs between culture conditions, consistent with the concept of limiting passage number in order to reduce cultureinduced transcriptome changes (O'Driscoll et al. 2006).

Published by Bioscientifica Ltd 
A
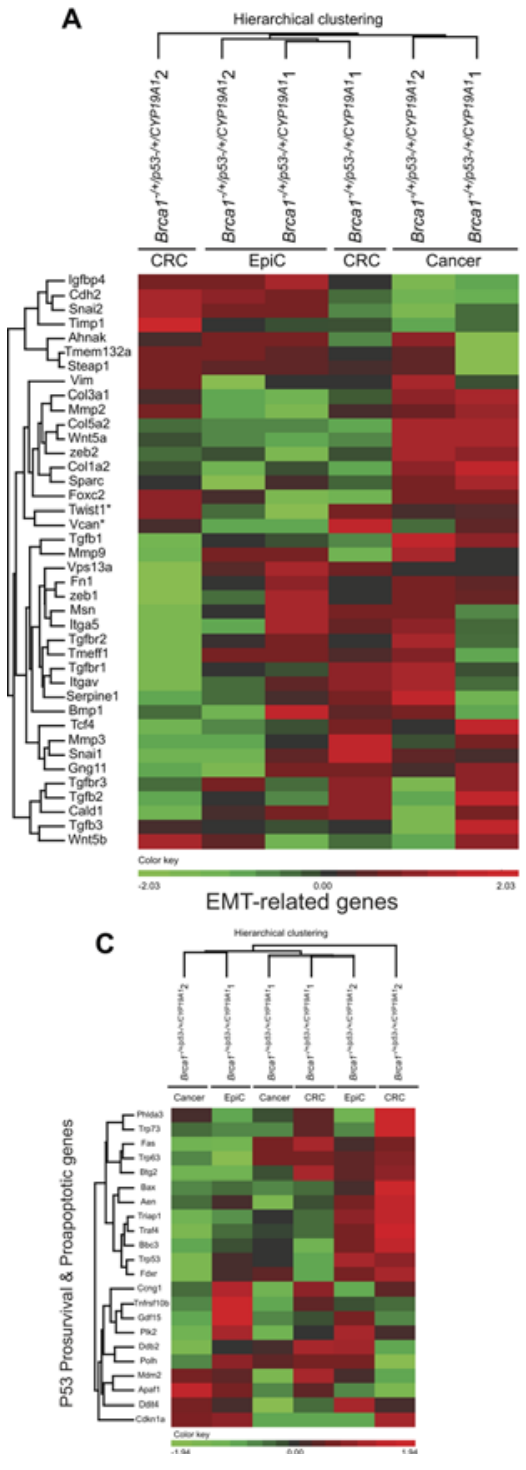

B
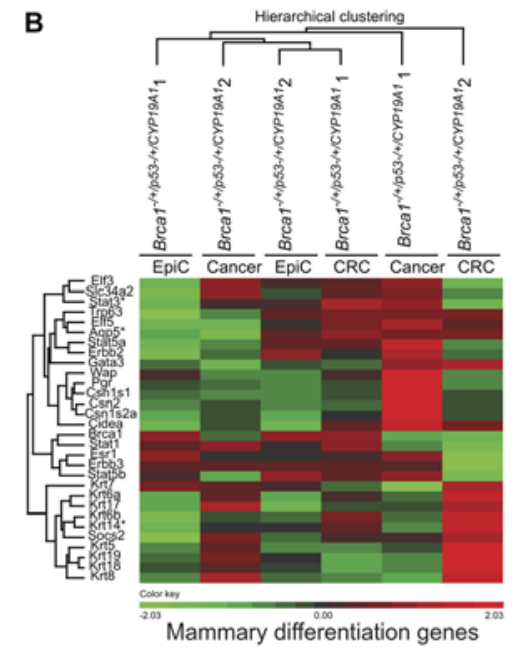

D

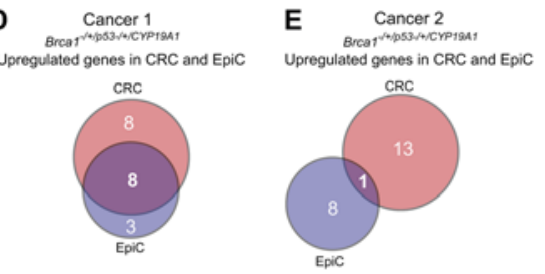

Downregulated genes in CRC and EpiC Downregulated genes in CRC and EpiC
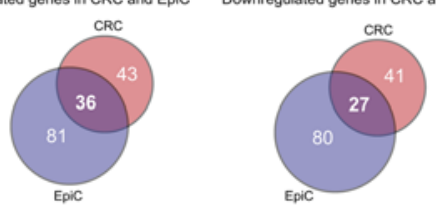

F BrCa1//ip53/4/CYP19A1

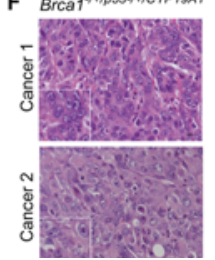

Figure 9

Limiting culture duration restrained significant changes in EMT-related, mammary

differentiation-related, and p53 pathway genes. (A) Dendrogram and heat map of unsupervised hierarchical clustering of FPKM values of EMT-related genes from paired EpiC and CRC cultures (P7) from two different Brca 1-/+/p53-/+/CYP19A1 cancer cell cultures and cancers they were derived from (cancer 1, cancer 2). *One EpiC/CRC pair, ${ }^{\star} P<0.05$, Cuffdiff_pval. (B) Dendrogram and heat map of unsupervised hierarchical clustering of FPKM values of mammary epithelial cell differentiation-related genes from paired EpiC and CRC cultures (P7) from two different Brca1-/+//P53-/+/CYP19A1 cancer cell cultures and cancers they were derived from (cancer 1 and cancer 2). *One EpiC/CRC pair, $\star P<0.05$, Cuffdiff_pval. (C) Dendrogram and heat map of unsupervised hierarchical clustering of FPKM values of p53-regulated prosurvival and proapoptotic genes from paired EpiC and CRC cultures (P7) from two different

Brca 1-///P53-/+/CYP19A1 cancer cell cultures and cancers they were derived from (cancer 1 and cancer 2). *One EpiC/CRC pair, ${ }^{\star} P<0.05$, Cuffdiff_pval. (D) Venn diagrams illustrating the overlap between DEGs significantly upregulated and downregulated in EpiC (blue) and CRC (red) cultures compared with the parent cancer 1 . (E) Venn diagrams illustrating the overlap between DEGs significantly upregulated and downregulated in EpiC (blue) and CRC (red) cultures compared with the parent cancer 2 . (F) Representative H\&E images of cancer 1 and cancer 2 that coincidently developed in the same Brca 1-/+/p53-/+/CYP19A1 mouse. Magnified images lower left. Images taken at $40 x$. Size bars $=10 \mu \mathrm{M}$.

\section{Discussion}

The high success rate of CRC for initial primary cell isolation and propagation was consistent with the previous reports (Chapman et al 2010, 2014, Liu et al. 2012, Saenz et al. 2014, Ligaba et al. 2015). Here, we demonstrated that mammary epithelial cells initially isolated in CRC can be transitioned to another culture methodology. An advantage of CRC is that growth of epithelial cells is selectively enhanced under the conditions used here (Liu et al. 2012). Therefore, not only did use of CRC for initial isolation rate increase the number of successful cultures, it also reduced fibroblast contamination.

Faster development of allografts with EpiC-cultured cells and acquisition of higher levels of EMT-related gene expression in allografts derived from CRC-cultured cells was consistent with the notion that EMT induces cancer stem cell characteristics in normal and transformed mammary epithelial cells, thereby increasing their tumorinitiating capacity (Mani et al. 2008). Higher levels of EMT genes under EpiC compared with CRC conditions paralleled previous reports of EpiC-cultured cells undergoing EMT (Nakles et al. 2013b) in comparison with retention of cuboidal architecture (Saenz et al. 2014) and suppression of the EMT-related TGFB pathway (Ligaba et al. 2015) under CRC conditions. Here, we documented upregulated TGFBR3 expression, a protein linked to a subtype of triplenegative breast cancers in women (Jovanović et al. 2014), under EpiC conditions. Provocatively, we found that TFBS for ZEB1, an EMT-linked gene, enriched in CRC-associated DEGs. However, FPKM levels for ZEB1 and its paralog ZEB2 were significantly lower in CRC compared with

Published by Bioscientifica Ltd 
EpiC conditions. Competitive binding between ZEB1 and alternatively acting Nkx2.5 has been described in vascular smooth muscle cells (Ponticos et al. 2004). A similar mechanism may act under CRC conditions. A second possibility for the absence of ZEB1-associated EMT under CRC conditions is the reported repressive action of p53 on ZEB1/ZEB2 (Sánchez-Tilló et al. 2012). The significant difference between numbers of injected sites developing into allografts between Brca1-replete and Brca1-deficient cells for both culture conditions may also be linked to EMT. BRCA1 has been described as an EMT suppressor (Bai et al. 2014).

Reports on the CRC technique have emphasized a link between increased p63 expression and retention of stem/ progenitor cells (Liu et al. 2012, Suprynowicz et al. 2012, Chapman et al. 2014, Brown et al. 2015, Ligaba et al. 2015). Here, we showed that in mammary epithelial cancer cells, p63 upregulation is part of a more generalized increase in expression levels of all $p 53$ gene family member genes including Trp53 and Trp73. Faster development of EpiCcultured allografts may have signified that, at least for these cancer cells, higher levels of Trp63 expression was not required for retention of cancer progenitor cells. If the goal for primary mammary epithelial cancer cell culture is allograft generation, the readily applied EpiC culture methodology enhanced allograft development. Presence of Allograft_Rejection as a significant hallmark gene set present in the transcriptomes of allografts and primary cancers was consistent with the expected presence of immune cells in vivo but not in vitro.

Limiting passage number to reduce culture-induced changes is not a new concept (O'Driscoll et al. 2006). Importantly, here, we showed that if isolation of primary mammary epithelial cells is primarily for transcriptome characterization, the less cumbersome EpiC culture methodology was acceptable. Moreover, we demonstrated that even though CRC promoted retention of epithelial cell architecture, this did not translate to superior preservation of the parent cancer transcriptome.

We documented differential activation of genetic networks linked to cancer biology in the two culture systems, p53 pathway under CRC conditions and TGFB pathway under EpiC conditions. Therapeutic approaches for both these pathways have been developed (Connolly et al. 2012, Duffy et al. 2014). A possible future direction would be to compare the response of targeted therapeutics in these paired cultures to establish how modulations in a baseline transcriptome might affect in vitro testing results. It is possible that this could improve the predictability of in vitro testing for some therapeutics (Hwu et al. 2006).
Studies here focused on triple-negative cancer cells that lack measurable levels of estrogen receptor (ER) alpha protein. A future direction is to explore utilization of these culture methodologies for ER-positive breast cancers. Small-molecule inhibitors of TGFB can increase maintenance of ER alpha expression in primary mammary epithelial cells (Fridriksdottir et al. 2015). One possibility would be to test how application of TGFB small-molecule inhibitors would influence ER alpha expression levels in these cultures.

In conclusion, both EpiC and CRC culture conditions were used to generate and propagate primary mammary epithelial cell cultures. CRC was the more efficient modality for initial generation and EpiC for allograft generation in these experiments. Because the two conditions result in culture-specific transcriptome alterations, the methodology selected for extended culture may be dictated by the experimental questions that are being posed. It is possible to move from either of these two specialized media to more generic culture condition such as DMEM. Either culture condition can be used to isolate primary mammary epithelial cells for transcriptome inspection, but passage should be limited for best approximation to intact tissue.

\section{Declaration of interest}

A M A, K K, S G, W W, X Z, B K, L H, and P A F declare no conflict of interest. Georgetown University has been awarded a patent by the United States Patent Office $(9,279,106)$ for conditional cell reprogramming. This technology has been licensed exclusively to a new biotechnology company, Propagenix, for commercialization. Georgetown University and the inventor on this manuscript $(X \mathrm{~L})$ receive payments and potential royalties from Propagenix.

\section{Funding}

Research performed here was supported by NIH NCI RO1 CA112176 (PAF), NIH NCI 5P30CA051008 (Histology and Tissue, Genomics and Epigenomics, and Animal Shared Resources), the Intramural Research Program of NIDDK/ $\mathrm{NIH}$, and King Khalid University, Abha, Saudi Arabia (AMA).

\section{Authors' contribution statement}

A M A involved in conception and design, data acquisition, analysis, and interpretation of the data; drafting and revising the manuscript; and final approval. $\mathrm{K} \mathrm{K}$ involved in bioinformatics conception and design, data acquisition, analysis, and interpretation; drafting and revising the manuscript; and final approval. S G involved in design, data acquisition, analysis, and interpretation of the data; drafting and revising the manuscript; and final approval. $\mathrm{W}$ W involved in data acquisition, manuscript revision, and final approval. $\mathrm{X} Z \mathbf{Z}$ involved in bioinformatics analyses, manuscript revision, and final approval. B K involved in acquisition of data and interpretation, manuscript revision, and final approval. $\mathrm{L} \mathrm{H}$ involved in data analysis, manuscript revision, and final approval.

Published by Bioscientifica Ltd. 
$X$ L involved in design, data analysis, manuscript revision, and final approval. P A F involved in conception and design, analysis and interpretation of the data, drafting and revising the manuscript, and final approval.

\section{Acknowledgments}

We thank Sarah Dabydeen for preparation of the sequencing libraries and Harold Smith, NIDDK, NIH for next-generation sequencing.

\section{References}

Allen MA, Andrysik Z, Dengler VL, Mellert HS, Guarnieri A, Freeman JA, Sullivan KD, Galbraith MD, Luo X, Kraus WL, et al. 2014 Global analysis of p53-regulated transcription identifies its direct targets and unexpected regulatory mechanisms. eLife $\mathbf{3}$ e02200. (doi:10.7554/ eLife.02200)

Assefnia S, Kang K, Groeneveld S, Yamaji D, Dabydeen S, Alamri A, Liu X, Hennighausen L \& Furth PA 2014 Trp63 is regulated by STAT5 in mammary tissue and subject to differentiation in cancer. Endocrine-Related Cancer 21 443-457. (doi:10.1530/ERC-14-0032)

Bai F, Chan HL, Scott A, Smith MD, Fan C, Herschkowitz JI, Perou CM, Livingston AS, Robbins DJ, Capobianco AJ \& Pei XH 2014 BRCA1 suppresses epithelial-to-mesenchymal transition and stem cell dedifferentiation during mammary and tumor development. Cancer Research 74 6161-6172. (doi:10.1158/0008-5472.CAN-14-1119)

Bhandary L, Whipple RA, Vitolo MI, Charpentier MS, Boggs AE, Chakrabarti KR, Thompson KN \& Martin SS 2015 ROCK inhibition promotes microtentacles that enhance reattachment of breast cancer cells. Oncotarget 6 6251-6266. (doi:10.18632/oncotarget)

Brown DD, Dabbs DJ, Lee AV, McGuire KP, Ahrendt GM, Bhargava R, Bhargava R, Davidson NE, Brufsky AM, Johnson RR, et al. 2015 Developing in vitro models of human ductal carcinoma in situ from primary tissue explants. Breast Cancer Research and Treatment 153 311-321. (doi:10.1007/s10549-015-3551-8)

Chapman S, Liu X, Meyers C, Schlegel R \& McBride AA 2010 Human keratinocytes are efficiently immortalized by a Rho kinase inhibitor. Journal of Clinical Investigation 120 2619-2626. (doi:10.1172/JCI42297)

Chapman S, McDermott DH, Shen K, Jang MK \& McBride AA 2014 The effect of Rho kinase inhibition on long-term keratinocyte proliferation is rapid and conditional. Stem Cell Research \& Therapy 5 60. (doi:10.1186/scrt449)

Connolly EC, Freimuth J \& Akhurst RJ 2012 Complexities of TGF- $\beta$ targeted cancer therapy. International Journal of Biological Sciences $\mathbf{8}$ 964-978. (doi:10.7150/ijbs.4564)

Darcy KM, Zangani D, Lee PH \& Ip MM 2000 Isolation and culture of normal rat mammary epithelial cells. In Methods in Mammary Gland Biology and Breast Cancer Research, pp 163-175. Eds. MM Ip \& BB Asch. New York, NY, USA: Springer US.

Diaz-Cruz ES, Cabrera MC, Nakles R, Rutstein BH \& Furth PA 2010 BRCA1 deficient mouse models to study pathogenesis and therapy of triple negative breast cancer. Breast Disease 32 85-97. (doi:10.3233/ BD-2010-0308)

Díaz-Cruz ES, Sugimoto Y, Gallicano GI, Brueggemeier RW \& Furth PA 2011 Comparison of increased aromatase versus ERo in the generation of mammary hyperplasia and cancer. Cancer Research $\mathbf{7 1}$ 5477-5487. (doi:10.1158/0008-5472.CAN-10-4652)

Dontu G, Abdallah WM, Foley JM, Jackson KW, Clarke MF Kawamura MJ \& Wicha MS 2003 In vitro propagation and transcriptional profiling of human mammary stem/progenitor cells. Genes \& Development 17 1253-1270. (doi:10.1101/gad.1061803)

Drasin DJ, Robin TP \& Ford HL 2011 Breast cancer epithelial-tomesenchymal transition: examining the functional consequences of plasticity. Breast Cancer Research 13 226. (doi:10.1186/bcr3037)
Duffy MJ, Synnott NC, McGowan PM, Crown J, O'Connor D \& Gallagher WM 2014 p53 as a target for the treatment of cancer. Cancer Treatment Reviews 40 1153-1160. (doi:10.1016/ j.ctrv.2014.10.004)

Fridriksdottir AJ, Kim J, Villadsen R, Klitgaard MC, Hopkinson BM, Petersen OW \& Rønnov-Jessen L 2015 Propagation of oestrogen receptor-positive and oestrogen-responsive normal human breast cells in culture. Nature Communications 6 8786. (doi:10.1038/ncomms9786)

Gawade S, Mayer C, Hafen K, Barthlott T, Krenger W \& Szinnai G 2016 Cell growth dynamics in embryonic and adult mouse thyroid revealed by a novel approach to detect thyroid gland subpopulations. Thyroid 26 591-599. (doi:10.1089/thy.2015.0523)

Gonzalez DM \& Medici D 2014 Signaling mechanisms of the epithelialmesenchymal transition. Science Signaling 7 re8. (doi:10.1126/ scisignal.2005189)

Grimm SL, Bu W, Longley MA, Roop DR, Li Y \& Rosen JM 2006 Keratin 6 is not essential for mammary gland development. Breast Cancer Research: BCR 8 R29. (doi:10.1186/bcr1504)

Groeneveld S 2012 Comparison of two culture techniques for the development of mammary cancer cell cultures from genetically engineered mouse models of human breast cancer. München, Germany: Ludwig-Maximilians-Universität München.

Haynes J, Srivastava J, Madson N, Wittmann T \& Barber DL 2011 Dynamic actin remodeling during epithelial-mesenchymal transition depends on increased moesin expression. Molecular Biology of the Cell 22 4750-4764. (doi:10.1091/mbc.E11-02-0119)

Hulsen T, de Vlieg J \& Alkema W 2008 BioVenn - a web application for the comparison and visualization of biological lists using area-proportional Venn diagrams. BMC Genomics 9488. (doi:10.1186/1471-2164-9-488)

Hwu P, Bedikian AY \& Grimm EA 2006 Challenges of chemosensitivity testing. Clinical Cancer Research 12 5258-5259. (doi:10.1158/ 1078-0432.CCR-06-1656)

Jones LP, Li M, Halama ED, Ma Y, Lubet R, Grubbs CJ, Deng CX, Rosen EM \& Furth PA 2005 Promotion of mammary cancer development by tamoxifen in a mouse model of Brca1-mutation-related breast cancer. Oncogene 24 3554-3562. (doi:10.1038/sj.onc.1208426)

Jones L, Tilli M, Assefnia S, Torre K, Halama E, Parrish A, Rosen EM \& Furth P 2008 Activation of estrogen signaling pathways collaborates with loss of Brca1 to promote development of ER $\alpha$-negative and ERo-positive mammary preneoplasia and cancer. Oncogene $\mathbf{2 7}$ 794-802. (doi:10.1038/sj.onc.1210674)

Jovanović B, Beeler JS, Pickup MW, Chytil A, Gorska AE, Ashby WJ, Lehmann BD, Zijstra A, Pietenpol JA \& Moses HL 2014 Transforming growth factor beta receptor type III is a tumor promoter in mesenchymal-stem like triple negative breast cancer. Breast Cancer Research 16 R69. (doi:10.1186/bcr3684)

Kang K, Robinson GW \& Hennighausen L 2013 Comprehensive metaanalysis of Signal Transducers and Activators of Transcription (STAT) genomic binding patterns discerns cell-specific cis-regulatory modules. BMC Genomics 14 4. (doi:10.1186/1471-2164-14-4)

Kang K, Yamaji D, Yoo KH, Robinson GW \& Hennighausen L 2014 Mammary-specific gene activation is defined by progressive recruitment of STAT5 during pregnancy and the establishment of H3K4me3 marks. Molecular and Cellular Biology 34 464-473. (doi:10.1128/MCB.00988-13)

Kim D, Pertea G, Trapnell C, Pimentel H, Kelley R \& Salzberg SL 2013 TopHat2: accurate alignment of transcriptomes in the presence of insertions, deletions and gene fusions. Genome Biology 14 R36. (doi:10.1186/gb-2013-14-4-r36)

Lehmann BD, Bauer JA, Chen X, Sanders ME, Chakravarthy AB, Shyr Y \& Pietenpol JA 2011 Identification of human triple-negative breast cancer subtypes and preclinical models for selection of targeted therapies. Journal of Clinical Investigation 121 2750-2767. (doi:10.1172/JCI45014)
(C) 2016 Society for Endocrinology Printed in Great Britain
Published by Bioscientifica Ltd 
Ligaba SB, Khurana A, Graham G, Krawczyk E, Jablonski S, Petricoin EF, Glazer RI \& Upadhyay G 2015 Multifactorial analysis of conditional reprogramming of human keratinocytes. PLOS ONE 10 e0116755. (doi:10.1371/journal.pone.0116755)

Liu X, Ory V, Chapman S, Yuan H, Albanese C, Kallakury B, Timofeeva OA, Nealon C, Dakic A, Simic V, et al. 2012 ROCK inhibitor and feeder cells induce the conditional reprogramming of epithelial cells. American Journal of Pathology 180 599-607. (doi:10.1016/j.ajpath.2011.10.036)

Livasy CA, Karaca G, Nanda R, Tretiakova MS, Olopade OI, Moore DT \& Perou CM 2006 Phenotypic evaluation of the basal-like subtype of invasive breast carcinoma. Modern Pathology 19 264-271. (doi:10.1038/modpathol.3800528)

Luo M, Brooks M \& Wicha MS 2015 Epithelial-mesenchymal plasticity of breast cancer stem cells: implications for metastasis and therapeutic resistance. Current Pharmaceutical Design 21 1301-1310. (doi:10.2174/1381612821666141211120604)

Mani SA, Guo W, Liao MJ, Eaton EN, Ayyanan A, Zhou AY, Brooks M, Reinhard F, Zhang CC, Shipitsin M, et al. 2008 The epithelialmesenchymal transition generates cells with properties of stem cells. Cell 133 704-715. (doi:10.1016/j.cell.2008.03.027)

Melino G, Memmi EM, Pelicci PG \& Bernassola F 2015 Maintaining epithelial stemness with p63. Science Signaling 8 re9.

Mitra A, Mishra L \& Li S 2013 Technologies for deriving primary tumor cells for use in personalized cancer therapy. Trends in Biotechnology 31 347-354. (doi:10.1016/j.tibtech.2013.03.006)

Moreno-Bueno G, Peinado H, Molina P, Olmeda D, Cubillo E, Santos V, Palacios J, Portillo F \& Cano A 2009 The morphological and molecular features of the epithelial-to-mesenchymal transition. Nature Protocols 4 1591-1613. (doi:10.1038/nprot.2009.152)

Nakles RE, Kallakury BV \& Furth PA 2013a The PPAR $\gamma$ agonist efatutazone increases the spectrum of well-differentiated mammary cancer subtypes initiated by loss of full-length BRCA1 in association with TP53 haploinsufficiency. American Journal of Pathology 182 1976-1985. (doi:10.1016/j.ajpath.2013.02.006)

Nakles RE, Millman SL, Cabrera MC, Johnson P, Mueller S, Hoppe PS, Schroeder T \& Furth PA $2013 b$ Time-lapse imaging of primary preneoplastic mammary epithelial cells derived from genetically engineered mouse models of breast cancer. Journal of Visualized Experiments: JoVE 72 50198. (doi:10.3791/50198)

Novaro V, Roskelley CD \& Bissell MJ 2003 Collagen-IV and laminin-1 regulate estrogen receptor alpha expression and function in mouse mammary epithelial cells. Journal of Cell Science 116 2975-2986. (doi:10.1242/jcs.00523)

O’Driscoll L, Gammell P, McKiernan E, Ryan E, Jeppesen PB, Rani S \& Clynes M 2006 Phenotypic and global gene expression profile changes between low passage and high passage MIN-6 cells Journal of Endocrinology 191 665-676. (doi:10.1677/joe.1.06894)

Olson MF 2008 Applications for ROCK kinase inhibition. Current Opinion in Cell Biology 20 242-248. (doi:10.1016/j.ceb.2008.01.002)

Palechor-Ceron N, Suprynowicz FA, Upadhyay G, Dakic A, Minas T, Simic V, Johnson M, Albanese C, Schlegel L \& Liu X 2013 Radiation induces diffusible feeder cell factor(s) that cooperate with ROCK inhibitor to conditionally reprogram and immortalize epithelial cells. American Journal of Pathology 183 1862-1870. (doi:10.1016/ j.ajpath.2013.08.009)

Ponticos M, Partridge T, Black CM, Abraham DJ \& Bou-Gharios G 2004 Regulation of collagen type I in vascular smooth muscle cells by competition between Nkx2.5 and deltaEF1/ZEB1. Molecular and Cellular Biology 24 6151-6161. (doi:10.1128/MCB.24.14.6151-6161.2004)
Robinson JT, Thorvaldsdóttir H, Winckler W, Guttman M, Lander ES, Getz G \& Mesirov JP 2011 Integrative genomics viewer. Nature Biotechnology 29 24-26. (doi:10.1038/nbt.1754)

Saenz FR, Ory V, AlOtaiby M, Rosenfield S, Furlong M, Cavalli LR, Johnson MD, Liu X, Schlegel R, Wellstein A, et al. 2014 Conditionally reprogrammed normal and transformed mouse mammary epithelial cells display a progenitor-cell-like phenotype. PLOS ONE 9 e97666. (doi:10.1371/journal.pone.0097666)

Sánchez-Tilló E, Liu Y, de Barrios O, Siles L, Fanlo L, Cuatrecasas M, Darling DS, Dean DC, Castells A \& Postigo A 2012 EMT-activating transcription factors in cancer: beyond EMT and tumor invasiveness. Cellular and Molecular Life Sciences 69 3429-3456. (doi:10.1007/ s00018-012-1122-2)

Shao MM, Chan SK, Yu AM, Lam CC, Tsang JYS, Lui PC, Law BK, Tan PH \& Tse GM 2012 Keratin expression in breast cancers. Virchows Archiv 461 313-322. (doi:10.1007/s00428-012-1289-9)

Suprynowicz FA, Upadhyay G, Krawczyk E, Kramer SC, Hebert JD, Liu X, Yuan H, Cheluvaraju C, Clapp PW, Boucher RC, et al. 2012 Conditionally reprogrammed cells represent a stem-like state of adult epithelial cells. PNAS 109 20035-20040. (doi:10.1073/ pnas.1213241109)

Taylor-Papadimitriou J, Stampfer M, Bartek J, Lewis A, Boshell M, Lane EB \& Leigh IM 1989 Keratin expression in human mammary epithelial cells cultured from normal and malignant tissue: relation to in vivo phenotypes and influence of medium. Journal of Cell Science 94 403-413. (available at: http://jcs.biologists.org/content/ joces $/ 94 / 3 / 403$.full.pdf)

Thorvaldsdóttir H, Robinson JT \& Mesirov JP 2013 Integrative Genomics Viewer (IGV): high-performance genomics data visualization and exploration. Briefings in Bioinformatics 14 178-192. (doi:10.1093/ bib/bbs017)

Tilli MT, Frech MS, Steed ME, Hruska KS, Johnson MD, Flaws JA \& Furth PA 2003 Introduction of estrogen receptor-alpha into the tTA/TAg conditional mouse model precipitates the development of estrogen-responsive mammary adenocarcinoma. American Journal of Pathology 163 1713-1719. (doi:10.1016/S0002-9440(10)63529-8)

Trapnell C, Williams BA, Pertea G, Mortazavi A, Kwan G, van Baren MJ, Salzberg SL, Wold BJ \& Pachter L 2010 Transcript assembly and quantification by RNA-Seq reveals unannotated transcripts and isoform switching during cell differentiation. Nature Biotechnology $\mathbf{2 8}$ 511-515. (doi:10.1038/nbt.1621)

Trapnell C, Roberts A, Goff L, Pertea G, Kim D, Kelley DR, Pimentel H, Salzberg SL, Rinn JL \& Pachter L 2012 Differential gene and transcript expression analysis of RNA-seq experiments with TopHat and Cufflinks. Nature Protocols 7 562-578. (doi:10.1038/ nprot.2012.016)

Trask DK, Band V, Zajchowski DA, Yaswen P, Suh T \& Sager R 1990 Keratins as markers that distinguish normal and tumor-derived mammary epithelial cells. PNAS 87 2319-2323. (doi:10.1073/pnas.87.6.2319)

Visvader JE \& Stingl J 2014 Mammary stem cells and the differentiation hierarchy: current status and perspectives. Genes \& Development 28 1143-1158. (doi:10.1101/gad.242511.114)

Yamaji D, Na R, Feuermann Y, Pechhold S, Chen W, Robinson GW \& Hennighausen L 2009 Development of mammary luminal progenitor cells is controlled by the transcription factor STAT5A. Genes \& Development 23 2382-2387. (doi:10.1101/gad.1840109)

Zambelli F, Pesole G \& Pavesi G 2009 Pscan: finding over-represented transcription factor binding site motifs in sequences from co-regulated or co-expressed genes. Nucleic Acids Research $\mathbf{3 7}$ W247-W252. (doi:10.1093/nar/gkp464)

Received in final form 10 May 2016

Accepted 6 June 2016

Accepted Preprint published online 7 June 2016 http://erc.endocrinology-journals.org DOI: 10.1530/ERC-16-0071
(C) 2016 Society for Endocrinology Printed in Great Britain
Published by Bioscientifica Ltd 